\title{
Los trabajadores y el capital foráneo en la industria petrolera mexicana*
}

\author{
Jonathan C. Brown* \\ UNIVERSIDAD DE TEXAS, AUSTIN
}

\begin{abstract}
Estudio sobre las relaciones entre los trabajadores petroleros y el Estado mexicano en el que se postula que

fueron los trabajadores, en lucha contra el deterioro económico de la industria petrolera, quienes presionaron al gobierno cardenista para emprender la expropiación.
\end{abstract}

$\mathrm{L}$ a expropiación de las compañías petroleras extranjeras parece definir el carácter nacional mexicano tan agudamente que cada quien ha tratado de apropiarse de su significado para sus propios fines. Incluso cuando se desarrolló el acontecimiento, Ios principales protagonistas trataron de explicar a qué equivalía la expropiación. Vicente Lombardo Toledano lo describió como una crisis que capitalistas extranjeros rapaces y ansiosos de dinero, aprovechaban para arrasar el patrimonio de la nación. Intelectual-

- La investigación para este artículo se pudo realizar gracias a la Fundación Mellon del Instituto de Estudios Latinoamericanos y a una beca del Policy Research Institute, ambos de la Universidad de Texas. Andrian Bantjes fue asistente de investigación. mente antiimperialista, Toledano indicó que la expropiación representaba nada menos que la emancipación económica de México. ${ }^{1}$ El presidente Lázaro Cárdenas también quiso explicar el acontecimiento en términos nacionalistas. En su discurso del 18 de marzo de 1938, transmitido por la radio y a nivel nacional, Cárdenas proyectó la crisis como de soberanía nacional. Las compañías petroleras se habían buscado la nacionalización, dijo, cuando desafiaron a los tribunales mexicanos, buscaron protección diplomática, intervinieron en política interna y provocaron la fuga de capital. ${ }^{2}$ Políti-

1 Véase Workers's, 1938; El Universal, 21 marzo 1938.

2 El Universal, 19 marzo 1938. 
cos, escritores y académicos -no todos ellos mexicanos- han interpretado subsecuentemente este acontecimiento básicamente dentro de parámetros internacionales. ${ }^{3}$ Pocos averiguan qué significó la nacionalización petrolera en términos de relación entre la clase trabajadora y el Estado, siendo esencialmente un asunto interno $y$, a fin de cuentas, una huelga de trabajadores petroleros lo que precipitó la crisis que condujo a la expropiación.

En este ensayo se dejan de lado las perspectivas estándar para examinar por qué, en la nacionalización petrolera mexicana además del patriotismo, la clase trabajadora mexicana jugó un papel prominente. Se postula que los trabajadores petroleros habían presionado recientemente al gobierno de Cárdenas para expropiar la industria petrolera mexicana; que empezaron a tomar los bienes de la industria petrolera antes de la propia nacionalización, y que inmediatamente después, asumieron el papel principal sustituyendo a los supervisores de las refinerías y de los campos petroleros, tanto extranjeros como mexicanos, por miembros leales del sindicato. Los trabajadores petroleros parecían bastante decididos a cerrar la industria petrolera, amenazando con arruinar la economía nacional que dependía del petróleo, si era necesario. En el camino, más que evitar el proceso político, se unieron al mismo. ¿Por qué los trabajadores condujeron a la expropiación de la industria petrolera, si es que

${ }^{3}$ El estudio clásico es el de Lorenzo Meyer, México, 1977. Véase también George Philip, Oil, 1982. lo hicieron? ¿Qué motivaciones desviaron su comportamiento, opuesto a la retórica de sus líderes? ¿Cómo engendró la lucha una dirigencia fuerte y a veces tiránica?

Este artículo propone que los petroleros mexicanos, que formaban parte de la "aristocracia laboral" del país, estaban reaccionando al deterioro económico dentro de la industria petrolera. Los trabajadores petroleros se organizaron de mala gana sólo para exigir seguridad en un empleo cuyos derechos de antigüedad eran tan importantes como los salarios. Sus reacciones ante esta inseguridad dieron lugar a luchas recíprocamente destructivas, intensas batallas y acción política militante. Estos trabajadores negociaron con empleadores y políticos y entre ellos mismos. Por necesidad, la lucha fortaleció a aquellos dirigentes laborales que pudieron obtener resultados, por los medios que fuera. La nacionalización de una industria debilitada y muy reducida, tal vez no fuera necesariamente la única solución que garantizara la seguridad de los trabajadores. Pero fue, a pesar de todo, el resultado lógico, dada la incapacidad de las compañías petroleras o su negativa a mitigar las necesidades de sus propios obreros.

\section{PROLETARIZACIÓN E INSEGURIDAD} DEL. EMPLEO

La industria petrolera de propiedad extranjera se desarrolló inicialmente durante la dictadura de Porfirio Díaz, y experimentó un auge en la primera guerra mundial, a fines de la cual, Mé- 


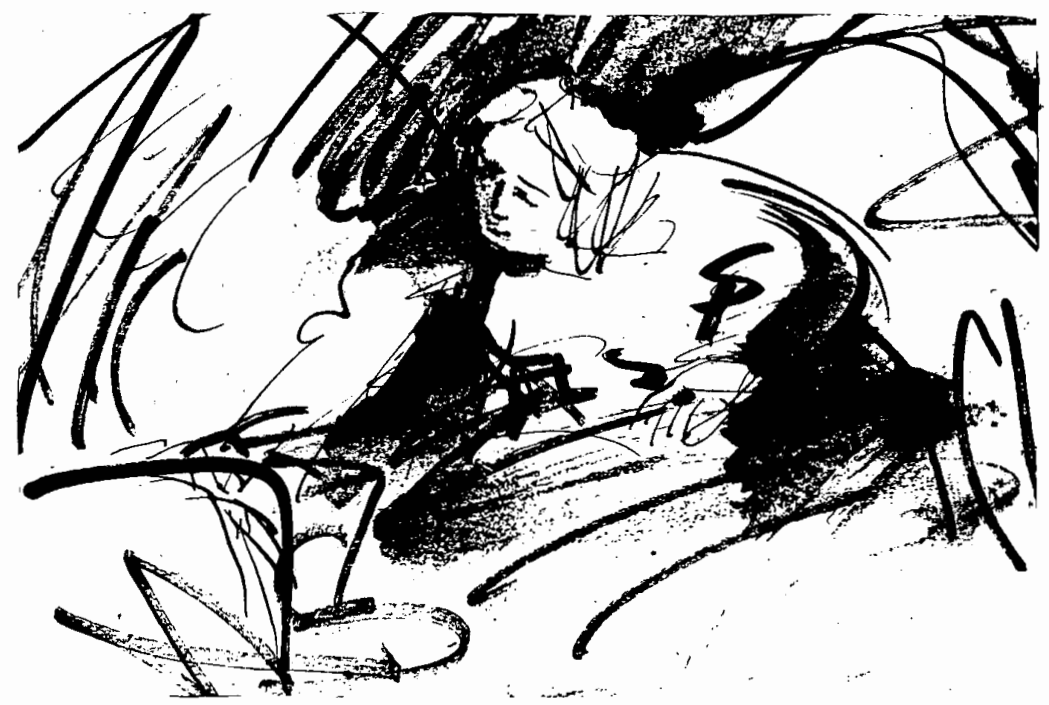

xico era el segundo productor de petróleo en el mundo después de Estados Unidos. Ubicados en la costa del golfo, esos campos petroleros escaparon a las peores depredaciones de la revolución mexicana. Aproximadamente 50000 mexicanos habían llegado a ser empleados por las compañías petroleras, y otros muchos miles emigraron a Tampico y Minatitlán para encontrar trabajo en la construcción y en las industrias de servicios. Desarrollaron así habilidades industriales, ganaron tres veces más que los peones agrícolas y cortaron sus vínculos con las aldeas campesinas, en una palabra, se proletarizaron.

Aún así, las consecuencias de su dependencia, cada vez mayor a causa de tener que vender su fuerza de trabajo, no fue inmediatamente manifiesta para los trabajadores petroleros. Los salarios altos y una producción floreciente ayudaron a los trabajadores mexicanos a tolerar salarios aún superiores y mayores privilegios otorgados a los estadunidenses. La luna de miel terminó en 1915. El dislocamiento económico de la revolución en casa y las penurias industriales producidas por la guerra mundial, elevaron el costo de vida. Cuando las compañías extranjeras se negaron a ajustar los salarios a la alza, los trabajadores comenzaron a organizarse. Aun antes de que la Constitución de 1917 reconociera sus de. rechos, mecánicos, caldereros, bomberos, montadores de tuberías, carpinteros y barqueros formaron gremios y lucharon para obtener salarios supe- 
riores y la paridad con los trabajadores extranjeros. Con frecuencia lograron, por lo menos, que se elevaran sus salarios. A pesar de todo, los trabajadores petroleros nunca habían deseado aplastar al capital extranjero. Tampoco participaron en los acontecimientos de la revolución en Tampico. ${ }^{4}$ Para 1919, su militancia se enfrió considerablemente a medida que la escasez de tiempos de guerra se aligeró en todo el mundo.

Después, el auge terminó bruscamente en 1920, alterando una vez más los niveles de vida de los obreros petroleros. El agua salada invadió los depósitos petroleros mexicanos y los precios se desplomaron debido a la sobreproducción en otras partes del mundo. En 1921 las compañías modernizaron sus operaciones y despidieron a varios miles de trabajadores. Aun cuando la industria decaía, sus propiedades se consolidaban. En 1919 la Royal Dutch Shell adquirió la mayor compañía con base en México, El Águila. Esta empresa británica manejaba aproximadamente $60 \%$ del negocio petrolero de la nación. La Standard Oil Company de New Jersey compró en 1932 la segunda mayor compañía de México, la Huasteca Petroleum Co. PetroMex, una compañía estatal y otros intereses extranjeros compartían sólo una pequeña porción de la produc. ción y los mercados.

La militancia laboral se hizo a tontas y a locas. Los trabajadores tenían motivos para sindicalizarse en tiempos de tensión económica, pero no lo hicie-

${ }^{4} \mathrm{~S}$. Leif Adelson, "Historia", 1982; Jonathan Brown, Oil (en preparación), cap. 7. ron: sufrieron calladamente la depresión de la posguerra; mas la escasa recuperaciốn motivó a los que aún conservaban sus empleos a organizarse de nuevo. Los viejos gremios formaron los núcleos de los sindicatos de las refinerías y terminales de mediados de los años 20. Los trabajadores de la refinería de El Águila, en Tampico, asistidos por políticos locales, fraguaron un notable triunfo en 1923: la huelga organizativa que obligó a la compañía a firmar el primer contrato colectivo en la industria. Alzas salariales, la jornada laboral de ocho horas e indemniza. ciones por despidos se contaron entre sus importantes conquistas. ${ }^{5}$ Pronto los siguieron los trabajadores de otras refinerías. Entre los dirigentes laborales existía una gran rivalidad. Competían con las compañías - y entre ellospor controlar los puestos de trabajo. Había resentimiento hacia supervisores y trabajadores extranjeros, en su mayoría estadunidenses, por sus salarios superiores, sus privilegios y su extremado racismo.

La militancia sindical cobró significación nacional. La CROM trató de incorporar a los sindicatos petroleros a su organización nacional pero con éxito limitado. El sindicato de la refinería de Minatitlán se afilió a la CROM sólo para que sus dirigentes nacionales en la ciudad de México negociaran, por una alta tarifa, el fin de su huelga en 1925 directamente con El Águila. ${ }^{6}$

5 S. Leif Adelson, "Coyuntura", 1979, pp. 632-660.

${ }^{6}$ Marjorie R. Clark, Organized, 1934, pp. 118-119; Barry Carr, Movimiento, 1976, pp. $161,187-188$. 
Sin embargo, Tampico se mantuvo fuera de las garras de los dirigentes sindicales nacionales, y las rivalidades entre las organizaciones laborales socavaron con frecuencia las conquistas. Este fue el caso de la huelga de 1925 contra la empresa Huasteca Petroleum Co. Los trabajadores de la refinería acababan de lograr la sindicalización de la mayoría de los trabajadores de los campos petroleros en el primer sindicato de empresa. Pero los nuevos funcionarios sindicales convocaron precipitadamente a huelga para obligar a la compañía a despedir a los dirigentes sindicales rivales. El gobierno expresó su desaprobación, los trabajadores rompieron filas, la huelga falló y el sindicato empresarial de la Huasteca Petroleum Co. se desintegró. Muchos de sus miembros nunca fueron recontratados. ${ }^{7}$ Los precios a la baja y un descenso adicional de la producción intimidaron, a fines de los años veinte, a los trabajadores dando lugar a que las compañías disminuyeran sus operaciones en México.

La Depresión contribuyó a aumentar los rencores que los petroleros -o lo que quedaba de ellos- estaban almacenando. La producción del crudo descendió aún más, a la vez que los precios internacionales caían en picada. Recién adquirida por la Jersey Standard, la Huasteca Petroleum Co. aprovechó los mercados estables para reconstruir su refinería en Mata Redonda, al otro lado del río Pánuco, en Tampico. Al volver a operar en 1932, la nueva refinería alivió en cierto modo el desempleo en la ciudad pero

${ }^{7}$ J.C. Brown, "Foreign", 1986, pp. 265-266. sus operaciones ahora eran más eficientes. ${ }^{8}$ Para los que aún conservaban el empleo, los salarios se redujeron entre 10 y $15 \%$, aunque un observador notó que los precios de los alimentos no variaron. Las compañías pequeñas clausuraron instalaciones y se fundieron con otras grandes. 9 En la Penn Mex Fuel Co., que pronto se fundiría con la Huasteca Petroleum Co., los reajustes de mano de obra de 1931 fueron los siguientes: ${ }^{10}$

- $15 \%$ de los trabajadores fueron reducidos temporalmente.

- 10\% iban a trabajar un día menos (cinco días en vez de seis).

- Y a 25\% de los trabajadores (los mejor pagados) se les redujeron los salarios una décima parte.

Los sindicatos de todas las compañías, grandes y pequeñas, tuvieron que aceptar los recortes. No era el momento de entrar en huelga cuando las compañías economizaban para seguir siendo competitivas dentro de la industria petrolera internacional: las compañías sólo eran vulnerables por la acción di-

8 C.E. Macy a Sec. of State, 1 abril 1931, 6 junio y 31 diciembre 1932, 29 marzo 1933, National Archives, Record Group 59 (RG 59), 812.00-Tamaulipas/23, /53, /92, 101 .

${ }^{9}$ L. Ralph Higgs, "Prevailing", 6 octubre 1932, National Archives, Washington, D.C., Record of the Department State, RG 84, Tampico Post Records, General Correspondance, Decimal File 850.4; "Penn Mex Fuel Co. contra trabajadores de la terminal Álvarez", 8 junio 1932, Archivo General de la Nación (AGN), México, Junta Federal de Conciliación y Arbitraje (JFCA), caja 69, exp. 9.

10 Pedro Noyola a Junta Regional Permanente de Conciliación, núm. 4, 7 septiembre 1931, JFCA, caja 53, exp. 20. 
recta-las huelgas-durante épocas de expansión. Los obreros petroleros habian sufrido extremadamente durante los grandes paros forzosos de 1921 y principios de los 30 . El descenso en la producción mexicana y las fluctuaciones de precios en el mercado mundial redujeron el número de trabajadores petroleros de 50000 en 1920 a 15000 en $1935 .{ }^{11}$ Aun así, junto con los trabajadores ferrocarrileros y mineros, los petroleros constituían la crema de la clase obrera mexicana. La militancia sindical se convirtió, en cierto modo, en un esfuerzo por preservar empleos privilegiados en un mercado laboral excedente. Cuando la militancia regresó a las refinerías y los campos petroleros, estos trabajadores "aristócratas" iban a procurarse la seguridad en el empleo con la misma intensidad con que habían sufrido condiciones de inseguridad durante la Depresión.

Dos acontecimientos, uno exógeno y el otro endógeno, proporcionaron la oportunidad de que los trabajadores petroleros se desagraviaran de pasados resentimientos. Primero, México salió de la Depresión. En 1934 las exportaciones habían vuelto a sus niveles de 1929 y los precios del petróleo se habían recuperado. Los rendimientos y fusiones realizados por las compañias extranjeras, habían permitido al país seguir siendo competitivo en mercados de exportación que contaban con un nuevo participante, Venezuela. El Águila había realizado el primer hallazgo nuevo de petróleo en

11 AGN, Archivo Histórico de Hacienda (AHH), Papeles de la Comisión Pericial, caja 1866-157, f. 44. una década en Poza Rica, que por cierto, llegó a producir $40 \%$ del total del petróleo crudo de México. La economía interna también reaccionó, y la demanda doméstica de petróleo subió significativamente. Alentada por el gobierno, El Águila construyó una nueva refinería fuera de la ciudad de México, en Azcapotzalco, y la conectó con Poza Rica a través de un oleoducto que atravesaba la sierra.

El segundo acontecimiento, sin relación alguna, fue político. La dirigencia nacional había fluctuado desde el asesinato del presidente electo, Álvaro Obregón en 1928, abriéndose oportunidades a que las organizaciones de masas fueran escuchadas e hicieran alianzas con los políticos que trataban de consolidar el poder nacional. La disolución de la CROM, una víctima del incipiente clima político, permitió que con la ruptura de Lombardo Toledano con la FROC se formara el núcleo de un grupo laboral nacional alternativo. La apertura política alentó a miles de campesinos y trabajadores de todo el país, a aprovechar el despegue económico para reorganizar sus grupos. La actividad huelguística ascendió junto con las demandas de reforma agraria. Coaliciones de políticos en busca de poder se inclinaron hacia la izquierda para captar esas demandas populares y el presidente Abelardo Rodríguez aprovechó la oportunidad de acopiar apoyo popular para un sucesor que pudiera resistir el poder de veto del ex presidente Plutarco Elías Calles. ${ }^{2}$ No

12 Véase especialmente Alan Knight, "Mexico", 1982-1989, 9 vols., vol. vII, pp. 3-82. 
obstante las posibles intenciones del Estado de controlar las demandas populares, el cardenismo no iba a ser un movimiento de reforma de arriba a abajo. La presión en la industria del petróleo empezó desde abajo en Minatitlán, y pronto se extendió a la ciudad de México, Tampico y Poza Rica. Los trabajadores petroleros, movidos por los amargos y desesperados recuerdos de la Depresión, estaban prestos a reconstruir sus organizaciones laborales desde abajo. El agente necesario iba a ser una dirigencia intermedia firme y exigente, los nuevos caciques laborales.

\section{REVOLUCIÓN EN MINATTTLÁN}

El menos productivo de los viejos campos petroleros mexicanos generó una temprana militancia laboral en virtud de la gravedad de sus crisis económicas. El Águila imperaba en el istmo. Sus bienes -varios pequeños campos petroleros de producción no importante, la terminal pétrolera de Nanchital en Puerto México, y la refinería en Minatitlán-fueron el escenario de una intensa competencia entre los sindicatos rivales para retener un número cada vez menor de puestos de trabajo. El manejo del control laboral en las fuentes de trabajo contribuyó a crear disputas faccionales entre los grupos que representaban a las diferentes plantas. Sus destructivas rivalidades contagiaron a la política nacional e impulsaron a contendientes locales a buscar alianzas externas con fines de dominio. Los dirigentes obreros de las refinerías triunfaron en los campos petro- leros y en los grupos de las terminales. Finalmente, cooperarían con sindicatos que representaban a otras refinerías hasta configurar su sindicato nacional.

La refinería había sido un enclave de la CROM desde la huelga de 1925. Pero la decadencia nacional de ésta proporcionaba la ocasión para que los rivales se disputaran el dominio. Contaban con la ayuda de las autoridades locales. Funcionarios de la compañía observaron que, en 1929, se había formado un pequeño sindicato de mecánicos en la refinería, para desafiar a la dominante cromista, Unión de Obreros. La rivalidad impidió la negociación del próximo contrato laboral, ya que las autoridades municipales favorecían al nuevo Frente Único, más tarde Alianza. El inspector laboral federal supervisó una elección entre los trabajadores, juzgando que la Unión de Obreros de la CROM estaba en mayoría, pero su fallo fue invalidado por la Secretaría de Industria. A su sustitución siguió la persecución oficial de la Unión, acusando a la CROM y a la compañía de operar juntos para defraudar a los trabajadores sus derechos legales. ${ }^{13}$

La lucha intersindical se intensificó cuando la compañía prosiguió con los despidos en el istmo hasta 1933. Todos los 17 hombres despedidos a principios de mayo pertenecían a la Unión de Obreros y ninguno a la Alianza. Lejos de ser despedidos, cuatro hombres

13 Theo. Dinstow a J.B. Body, 11 febrero 1929, F.M. Davies a Body, 10 septiembre 1930 , en Shell International Oil Company, Londres, Group History, México. 
de la Alianza fueron reasignados dentro de la planta. Como la administración explicó al inspector laboral, El Águila tenía 1300 obreros en su planta de Minatitlán y debía dar preferencia al sindicato mayoritario. ${ }^{14}$ Las tensiones laborales penetraron a menudo la política local y viceversa. Manuel Fuentes era, en 1933, un agrarista a la vez que presidente de la Congregación de Gavilán Norte y vigilante en el campo petrolero de Agua Dulce. Los hombres que lo asesinaron eran trabajadores de El Águila, pero como funcionarios municipales, también eran sus enemigos políticos. ${ }^{15}$ ¿Dónde terminaba la violencia política y empezaba la violencia laboral en tal situación?

Cuando ElÁguila empezó a recontratar trabajadores, la competencia entre los obreros y sus representantes se hizo más intensa. En el campo petrolero de Agua Dulce, el sindicato minoritario, el Sindicato Único, se molestó cuando la compañía dejó de deducir sus cuotas sindicales, privándolo virtualmente de su existencia. Agentes del mismo acusaron a la compañía de favorecer a su rival, la Agrupación Blanca. Además, aquellos de sus miembros que habían sufrido degradación durante la Depresión, descubrian ahora que sus antiguos puestos de trabajo iban a manos de obreros con menor habilidad y antiguiedad. Pocos de sus

${ }^{14}$ Salvador García y Jesús Corral, [Informe], 27 mayo 1933, AGN, Departamento Autónomo de Trabajo (DAT), caja 9, exp. 13.

15 Emiliano García a Isaurio Acosta, 24 mayo 1933, Andrés Guillot a Rodríguez, 5 julio 1933 , AGN, Papeles Presidenciales, Fondo Abelardo Rodriguez (FAR), 524/317. hombres estaban siendo reinstalados en sus antiguos puestos. ${ }^{16}$ Pero el sindicato mayoritario en Agua Dulce (fuera o no un grupo "blanco"), no dejó a El Águila manos libres en cuanto a personal. Dos taladradores mexicanos del campo petrolero cercano de Francita, entrenados en algo que los obreros estadunidenses habían monopolizado tanto tiempo, quedaron cesantes cuando Francita fue reducido. El Águila había querido transferir a los hombres a Agua Dulce, pero el mayoritario Sindicato de Obreros bloqueó su decisión. ${ }^{17}$

Pensaban los dirigentes sindicales -y los funcionarios gubernamentales coincidian con ellos- que un taller cerrado iba a reducir en mucho la intensa competencia y división entre los trabajadores. Los sindicatos iban a decidir cuáles solicitantes enviar a cubrir las vacantes de la compañía. Los trabajadores libres podían permanecer en sus puestos, pero, al dejarlos, iban a ser reemplazados por otros miembros del sindicato. La llamada "claúsula de exclusión" también tenía sus rasgos disciplinarios. Si el sindicato retiraba la membrecía a un trabajador, la compañía estaba obligada a expulsarlo. La claúsula de exclusión era la principal demanda de los trabajadores petroleros del istmo en la primavera de 1934, y todas las compañías se oponían a ella. El Águila la tildó de injusta. Mientras las leyes laborales ilustradas del país limitaban la explotación de los

${ }^{16}$ José Pera y otros al Presidente, 15 junio 1933, FAR, 561.8/130.

${ }^{17}$ Hermenegildo Vázquez y otros al Presidente, FAR, 561.8/130. 
trabajadores por patronos injustos, reclamaba El Águila, no hacían nada por frenar los abusos de los jefes laborales inmorales. La claúsula de exclusión también promovía la mediocridad en el lugar de trabajo, informaba El Águila al presidente, Abelardo Rodríguez: 18

[En la práctica] probablemente significará que, bajo un pretexto u otro, los trabajadores más diestros y competentes, con el mayor número de años de servicio, quienes por razón de su competencia y experiencia estén ocupando los puestos mejor retribuidos y de mayor responsabilidad, paulatinamente serán expulsados del Sindicato y, por tanto, despedidos por la Compañía, dando esto por resultado que dichos trabajadores se encontrarán sin trabajo después de muchos años de servicio. No se escapará a su ilustrado criterio la lógica de esta conclusión, por razón del hecho de que, en el caso de todos los Sindicatos en los campos petroleros y las refinerías, la mayoría de sus miembros está compuesta, por razón natural, de los trabajadores más ignorantes y menos diestros.

¿Y qué sentían algunos trabajadores mexicanos acerca de la administración extranjera? Desde el istmo, un trabajador escribió:

Que El Águila trata a los trabajadores mexicanos, llegando a casi establecer un estado de superioridad racial entre los nuestros y los súbditos ingleses que en ella sirven. Expone que en esa re-

18 P.J. Jonker al Presidente, 2 mayo 1934, FAR, $671.4 / 51$.

LOS TRABAJADORES Y EL CAPITAL FORÁNEO gión, los trabajadores mexicanos en todas las ramas de esa empresa, disfrutan de un salario muy inferior a los extranjeros que desempeñan las mismas labores, siendo además objeto de toda clase de atropellos y arbitrariedades en sus derechos. Sus habitaciones son siempre las peores y más antihigiénicas. ${ }^{19}$

Cuando los trabajadores de la terminal de Nanchital entraron en huelga en mayo, exigían tanto la cláusula de exclusión como la sindicalización obligatoria de todos los extranjeros. Algunos diplomáticos estadunidenses pensaron que ésta era una forma de los mexicanos para deshacerse de la competencia extranjera en los mejores puestos de trabajo. ${ }^{20}$ Integrar a todos los extranjeros a los sindicatos, expulsarlos después, obligando así a las compañías a rescindir sus contratos sin indemnización.

Cuando la gran huelga llegó al istmo en mayo de 1934, 3500 petroleros abandonaron el trabajo. En algún momento del mes anterior, Luis R. Torres y su Unión de Obreros de Minatitlán habían renunciado silenciosamente a su afiliación a la CROM. ${ }^{21} \mathrm{El}$ grupo dominante pronto se rebautizó comoSindicato de Trabajadoresy, una vez más y con violencia se apoderó de la representación mayoritaria de la refinería y se incorporó libremente a una Federación de Sindicatos de Trabaja-

19 Gabriel Mirón al Presidente, 22 febrero 1933, FAR, 561.8/97.

${ }^{20}$ Macy a Sec. of State, 31 mayo 1934, RG 59 812.00-Tamaulipas/150.

21 Torres a J.H. Dyball, 6 abril 1934, DAT, caja 46 , exp. 1 . 
dores de la Industria del Petróleo y sus Derivados, formada por los sindicatos de Agua Dulce, Las Choapas, Francita, Nanchital, los estibadores de Minatitlán y la Alianza minoritaria de la refinería: ${ }^{22}$ La huelga comenzó el 12 de mayo.

La demanda principal era la claúsula de exclusión, que los dirigentes laborales querian aplicar para combatir a sus sindicatos "blancos" rivales. El Águila solicitó que la Junta Federal de Conciliación y Arbitraje (JFCA) declarara la huelga ilegal porque uno de los sindicatos participantes no había dado el debido aviso. Los dirigentes sindicales se mostraron menos que unidos en su respuesta. No pudieron ponerse de acuerdo en la selección de un comité que los representara y faltaron a la audiencia programada en la ciudad de México. ${ }^{23} \mathrm{~A}$ pesar de todo, los sindicatos forzaron a la compañía a acceder a un arbitraje presidencial obligatorio. Las compañías estadunidenses se enfurecerían con la compañía inglesa por haber cedido ante los trabajadores: pronto, el laudo presidencial de 1934, iba a alentar a otros petroleros a solicitar un contrato igual al de Minatitlán. Éste consistia en: ${ }^{24}$

- La claúsula de exclusión.

- El establecimiento de escalafones 1, f. 48.

22 Doc. dtd., 6 mayo 1934, DAT, caja 28, exp.

23 Thomas D. Bowman, "El Águila and other strike movements in Mexico", 11 junio 1934, RG $59,812.5045 / 168$.

${ }^{24} \mathrm{~J}$. Rennow a Luis J. Rodríguez, 15 diciembre 1934, FI.C 432.2/8, E1. Para el laudo de 1934, véase FLC $432.2 / 2$. y derechos de antigüedad para promoción.

- Reducción de la semana laboral a 46 horas y media.

- Una indemnización básica de tres meses en caso de despidos.

- Medio salario para los trabajadores enfermos.

- Beneficios médicos para las familias de los trabajadores.

- Pago igual por trabajo igual.

- Prestaciones por retiro.

- Pago obligatorio por días de descanso.

- Aumentos salariales para trabajadores que ganaran menos de 5 pesos al día.

Muy pronto la compañía iba a ver cómo funcionaría la claúsula de exclusión. Los sindicatos activaban la claúsula cuando resentían cualquier pérdida de ventaja en su lucha con otros sindicatos por su radio de acción. El sindicato de Nanchital expulsó a Miguel Beltrán cuando pidió al tesorero de El Águila que no dedujera sus cuo. tas sindicales de su cheque de pago. El sindicato lo consideró como una amenaza para la unidad de los trabajadores. ${ }^{25}$ La claúsula de exclusión también dio a los dirigentes laborales la capacidad adicional de interrumpir la transferencia de personas dentro de la industria. Por ejemplo, el sindicato de la refinería de Minatitlán, reclamó jurisdiscción sobre el nuevo campo exploratorio de Campo Tigre, para reservar esos puestos de trabajo a 51 traba-

25 Docs. dtd., 21 y 22 enero 1935, DAT, cajà 28, exp. 1 ff. $764-765,780$. 


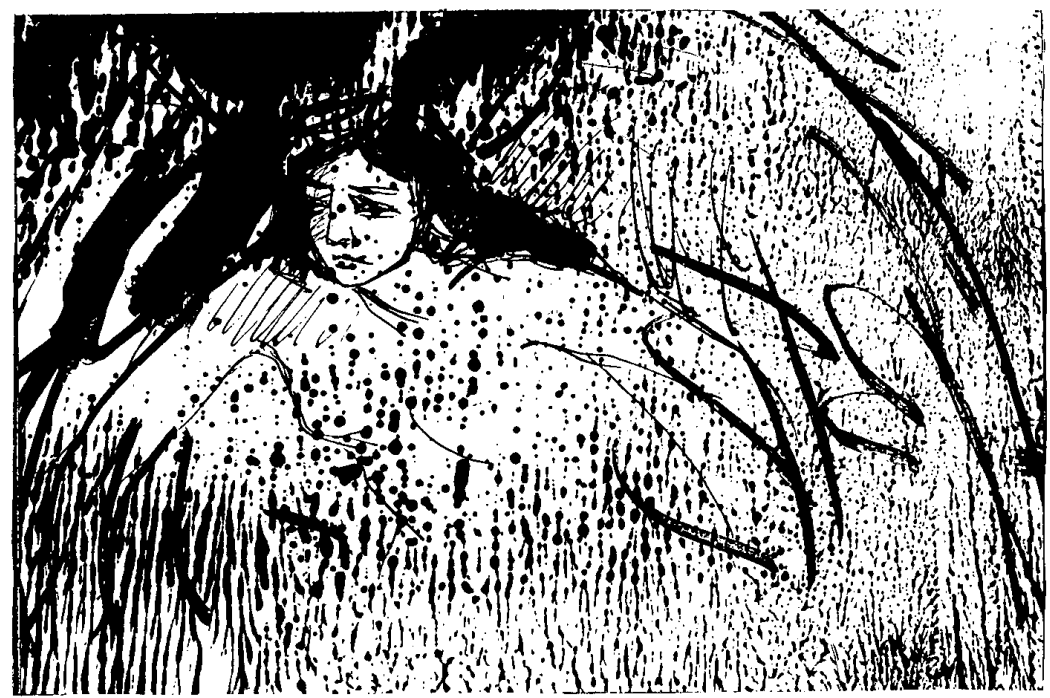

jadores de tiempo parcial (eventuales) de la refinería. Después, cuando algunos de los trabajadores fueron transferidos a la terminal de Nanchital, su sindicato pidió su despido por considerarlos hostiles. ${ }^{26} 119$ hombres dedicados a la perforación estaban sin trabajo en Agua Dulce, ya que el taller estaba cerrado; en este caso la compañía estaba obligada a dejarlos ir y a pagarles la indemnización completa. También, a la hora en que Agua Dulce fue eliminada en fases, sus trabajadores enfrentaron la oposición del sindicato a su transferencia a Las Choapas. Agua Dulce fue escenario de mucha

${ }^{26}$ Docs. dtd, 27 junio, 26 diciembre 1934 , DAT, caja 28, exp. 1 ff. 332 y 591-595. agitación laboral en 1935 y 1936 cuando el sindicato petrolero, incluso con la claúsula de exclusión, resultó incapaz de salvar puestos de trabajo en otro campo petrolero en decadencia en el istmo. ${ }^{27}$ Estos petroleros sin trabajo no fueron exactamente bien recibidos por sus compañeros en Poza Rica.

Ni la claúsula de exclusión, ni el contrato colectivo, ni la presencia de administradores ingleses relativamente ilustrados (en oposición a los estadunidenses de línea dura) iba a llevar la paz laboral al istmo de Tehuantepec.

${ }^{27}$ P.J. Jonker al Presidente, 3 septiembre 1934, FAR, 561.4/51.7; doc. dtd., 5 octubre 1934, DAT, caja 28, exp. 1, f. 449; extractos 4 y 13 febrero y 6 marzo 1935, AGN, Papeles Presidenciales, Fondo Lázaro Cárdenas (FLC), 432/69. 
Habiendo consolidado sindicatos mayoritarios dentro de sus propias instalaciones, los dirigentes laborales empezaban ahora a pelear entre ellos por cuestiones de transferencias e igualación de pago entre las refinerías y los campos petroleros. Sobre todo, su desacuerdo era cuál de ellos iba a representar a los trabajadores petroleros del istmo a nivel regional y nacional. Era una lucha crítica entre la refinería de Minatitlán y la terminal de Nanchital. Cuando Nanchital parecía cobrar ventaja en la Federación de Sindicatos de Trabajadores, Luis Torres, representante de los trabajadores de la refinería, denunció a sus dirigentes como "personas extrañas que sólo buscan su mejoramiento personal", y se retiró. ${ }^{28} \mathrm{El}$ sindicato de la refinería de Minatitlán pudo nombrar posteriormente a Torres como representante laboral en la Comisión Mixta local. A partir de entonces, Nanchital fue reacia a someter sus quejas sobre accidentes a esta comisión. ${ }^{29}$ Nanchital trató de rebasar el flanco de sus rivales del istmo formando un sindicato nacional de trabajadores petroleros. Esta vez, los hombres de la refinería de Minatitlán pidieron la ayuda de los sindicatos de refinación de Tampico para librar la amenaza. Por último, como veremos, los trabajadores de la refinería -no el más pequeño de los grupos de terminales y de campos petroleros-iban a crear exitosamente el sindicato nacional petrolero.

\footnotetext{
${ }^{28}$ Luis R. Torres y otros al Presidente, 10 julio 1934, FAR, 06/22.

${ }^{29}$ Docs. dtd., 10 y 23 enero 1935, DAT, caja $28, \exp .1$, ff. 383,797 .
}

La lucha interna y el hecho de que los sindicatos petroleros de otras partes empezaran a conquistar mejores contratos que el acogido al laudo de 1934, mantuvo al istmo en un estado de constante agitación hasta la expropiación. El inspector laboral federal en Minatitlán expresó la opinión de que muchos trabajadores no estaban a favor de huelgas constantes y amenazas de huelga, sino bajo la influencia de "líderes faltos de escrúpulos". ${ }^{30}$ Una cosa que el arbitraje de Abelardo Rodríguez podía haber logrado era la total conversión de antiguos dirigentes de la CROM a la coalición popular en apoyo de Lázaro Cárdenas. En la primera confrontación Cárdenas-Calles de 1935, los líderes antiguamente cromistas dirigieron el Sindicato de Trabajadores en una marcha victoriosa. " $i V i v a$ el general Cárdenas!”, gritaban, “iAbajo los jefes máximos!".31

\section{SINDICALIZACIÓN EN AZCAPOTZALCO}

El Águila, la compañía petrolera más grande de México, cumplía un compromiso a largo plazo con el gobierno cuando, en 1930, empezó la construcción de la refinería de Azcapotzalco, en las afueras de la ciudad de México. No podía haber llegado en un momento más propicio. El Águila daba empleo a varios centenares de trabajadores mexicanos de la construcción. La mayoría eran personas inexpertas,

30 Doc. dtd., 24 enero 1935, DAT, caja 28 , exp. 1, ff. 816.818.

31 Doc. dtd., 28 junio 1935, FLC 432/87. 
ocupadas en trabajo transitorio con contratos individuales que no les garantizaban derechos hasta la vejez. Los trabajadores especializados tenían un periodo de prueba de tres días antes de poder contratarse permanentemente.

La Compañía será la única capacitada -anunciaron sus funcionarios-para determinar el número de trabajadores que se necesitan en cada obra de construcción y las fechas en que ya no sean necesarios los servicios de cada uno de sus trabajadores por la disminución de las obras. ${ }^{32}$

Acostumbrada desde hacía mucho a las demandas de los obreros mexicanos, El Águila trató de evitar obviamente la agitación laboral en sus nuevas instalaciones.

Un núcleo de trabajadores organizó, a pesar de todo, el Sindicato de Obreros y Empleados de la refinería de El Águila, Azcapotzalco, en agosto de 1931, mucho antes de que la refinería se pusiera en marcha. Respondiendo a la nueva ley laboral de aquel año, presentaron a la compañía un contrato colectivo que contenía la claúsula de exclusión. Pedían que la compañía reconociera al sindicato, aboliera los contratos individuales y aceptara a sus miembros para nuevos puestos de trabajo. ${ }^{33} \mathrm{El}$ incipiente Sindicato de Obreros afirmaba su afiliación a la CGT, una confederación na-

32 J.M. Torres al JFCA, 21 mayo 1931, JFCA, C51, E2.

33 Sindicato de Obreros al JFCA, 4 agosto 1931 , JPCA, caja 51, exp. 5, ff. 3-6. cional desde hacía tiempo opuesta a la CROM. Sus dirigentes sostenían que la compañía tenía intención de reemplazar a sus empleados actuales con trabajadores de la CROM de Minatitlán. La compañía respondió que el trabajo de construcción era transitorio y que las operaciones de refinamiento necesitaban trabajadores con habilidades especializadas. Pero un sondeo entre los trabajadores patrocinado por el gobierno indicaba que sólo uno de cada cinco estaba a favor de la huelga. ${ }^{34}$ En cuanto el contrato del Sindicato de Obreros terminó, un grupo sindical rival presentó sus demandas a la compañía. Afiliado a la CROM, el Sindicato Único de la Refinería El Águila presentó un contrato colectivo mucho menos exigente a la compañia. Una segunda votación supervisada por el gobierno, adjudicó a los dirigentes del Único, por un margen de 4 a 1, la representación de los constructores de la refinería. ${ }^{35}$ Pero lasoperaciones aún estaban por comenzar.

Sin la claúsula de exclusión, el Sindicato Único pronto perdió el control de los trabajadores de la refinería. El Águila otorgó la construcción de la nueva instalación a contratistas que usualmente empleaban nuevos elementos para cada proyecto. Para cuando se puso en marcha en octubre de

${ }^{34}$ Sindicato a JFCA, 7 agosto 1931, Pieter Jan Jonker al JFCA, 12 agosto 1931, JPCA, C51, E5; "Sindicato de Obreros y Empleados de la Cía. Mexicana de Petróleo El Águila: Huelga", 17 septiembre 1931, JFCA, caja 66, exp. 1.

${ }^{35}$ Luis E. Galindo, [Reporte], 23 octubre 1931, JFCA, caja 51, exp. 5. La construcción de la refinería ocupó a 536 trabajadores. 
1934, ni uno solo de los trabajadores pertenecía al equipo que había comenzado la obra en 1930. Una mayoría había firmado contrato durante los diez meses anteriores. Esta alta rotación de personal puede que haya debilitado el control del Sindicato Único sobre los obreros ya que una lucha por la dirigencia dividió a dicho sindicato en dos facciones. Otra elección de julio de 1934, supervisada por el gobierno, dio a una facción del único una mayoría de dos a uno sobre la otra. ${ }^{36}$

Pero los dirigentes derrotados no se daban por vencidos. Se incorporaron al antiguo sindicato minoritario, el Sindicato de Obreros, y forjaron una alianza con Lombardo Toledano. Cada sindicato rival acusaba al otro de ser el sindicato blanco y culpaba a la compañia de despedir a sus propios partidarios. Estallaron luchas en el sitio de la construcción y funcionarios de $\mathrm{El}$ Águila culparon al Sindicato Único de propaganda desorganizadora durante las horas de trabajo. Finalmente, el Sindicato de Obreros presentó un contrato colectivo a El Águila y amenazó con entrar en huelga si la compañía no lo firmaba. El Sindicato Único tomó represalias pidiendo que la compañia despidiera a los dirigentes del Sindicato de Obreros. El presidente Rodríguez trató de que ambos grupos sindicales se disolvieran a fin de formar uno solo. El Único se negó y poco después de que Cárdenas tomara posesión, los dirigentes del Sindicato de Obreros reclutaron personal de oficina para el des-

36 Bernardo G. Gortera y otros, [Reporte], 3 julio 1934, FAR, 561.8/272. pacho de El Águila en el centro de la ciudad reconstituyéndose como Sindicato de Trabajadores y rechazando entonces el contrato propuesto por la compañía, idéntico al que los trabajadores de Minatitlán acababan de ganar. Eventualmente, el nuevo Sindicato de Trabajadores, mayoritario, ganó un contrato mejorado con la claúsula de exclusión. ${ }^{37} \mathrm{La}$ única refinería donde los funcionarios de El Águila habían esperado poder evitar problemas laborales, tenía ahora un sindicato agresivo, en muy buenos términos con Lombardo Toledano y con amigos simpatizantes en el Departamento de Trabajo de Cárdenas. La lucha se había dado entre sindicatos rivales, pero la compañía era el perdedor final. El nuevo contrato colectivo hizo bastante difícil para la compañía despedir a alguien que no deseara irse. En Tampico estaba ocurriendo en gran parte lo mismo.

\section{PODER Y HEGEMONÍA EN TAMPICO}

Como en otras partes, los obreros sufrieron en Tampico el desempleo de la Depresión calladamente. Sin embargo, cuando las compañías petroleras comenzaron a recontratar gente en 1933, ellos empezaron también a tomar el asunto en sus manos luchando, tanto entre ellos como contra su dependencia del lugar industrial de tra-

37 John S. Little, "Strike Movements", 10 diciembre 1934, 7 enero 1935, RG 59, 812.5045/ 184 y /188; J Rennow a Luis I. Rodríguez, 15 diciembre, Armando T. Vázquez al Presidente, 20 diciembre 1934, Fl. 432.2/8, exp. 1. 
bajo. Pidieron la asistencia y el reconocimiento de las autoridades políticas locales y nacionales y lo obtuvieron.

En la refinería más grande de México, El Águila, ubicada en el barrio industrial de Tampico llamado Ciudad Madero, trabajaba la mayor concentración -quizás 5000 - de trabajadores mexicanos calificados y semicalificados del país. Desde 1923, el Sindicato de Obreros tenía el contrato colectivo de la refinería. Contenía una jornada de $\mathbf{8}$ horas, una semana de vacaciones pagadas e indemnización por despido. De 1928 a 1932, muchos de sus trabajadores habían recibido indemnización por despido en uno u otro momento. Los sindicalizados no tenían derechos especiales de trabajo, salvo los de su calificación o experiencia previa en El Águila. ${ }^{38}$

A pesar de todo, los trabajadores de esta refinería siguieron peleando a los otros sindicatos cualquier jurisdicción sobre puestos de trabajo. El dirigente Serapio Venegas, militante de los años veinte, había sido expulsado por votación del directorio del Sindicato de Obreros; después, en 1932, fue asesinado. En aquel momento, este sindicato se estaba tambaleando por el gran número de sus agremiados despedidos de la refinería de Tampico. ${ }^{39} \mathrm{La}$ nueva dirigencia laboral luchaba por reconquistar algo de su antigua hegemonía de otros tiempos, pero su sindicato se dividió en dos facciones. Trescientos de sus trabajadores formaron

38 "Sindicato de Obreros contra El Águila", 23 mayo 1932, JFCA, caja 69, exp. 8.

39 Walter P. McConaughy a Sec. of State, 2 agosto 1932, RG 59, 812.00/-Tamaulipas/76. en marzo un sindicato rival, llamado Sindicato de Empleados, y presentó a la refinería un contrato laboral que la compañía ignoró. También estalló una batalla entre petroleros y barqueros que trabajaban en el río Pánuco para la misma. En cierto momento, unos pistoleros emboscaron y mataron al dirigente de una de las facciones, crimen del que fueron acusados cinco organizadores obreros. ${ }^{40}$ Era un confuso asunto en que también estaban implicados funcionarios estatales y locales.

La lucha intersindical se había intensificado desde que la compañía empezó a recontratar personal a partir de mayo de 1933. En la reapertura de la fábrica de barriles de la refinería de Tampico, el Sindicato de Empleados, producto de la ruptura, acusó a los funcionarios de la compañía de conspirar con el Sindicato de Obreros, mayoritario, para excluira sus miembros. Hombres armados, apostados en la entrada de esta fábrica, amenazaron incluso a miembros del sindicato minoritario. ${ }^{41}$ La competencia por estos puestos de trabajo era, en efecto, muy fuerte ya que los agricultores también aspiraban a trabajar como petroleros.

Pues un sinnúmero de familias organizadas carecen de pan para sus hijos -escribió un grupo campesino ubicado cerca de Tampico-, y no es justo que gentes de otros lugares utilicen la citada Compañía [El Águila] en trabajos de

40 G. Polanco G. al Presidente, 14 abril, Sindicato de Empleados y Obreros al Presidente, 25 abril 1933, FAR, 561.5/40; 501.3/40.

41 R. Castillo a Juan de Dios Bojórquez, 3 y 10 mayo 1933, DAT, caja 9, exp. 13. 
referencia quitándonos el derecho legal que nos asiste en el presente caso. ${ }^{42}$

Los administradores extranjeros de la refinería aún decidían a quién emplear y dónde, pero el exceso de brazos motivaba a los que ya tenían empleo a conseguir algo de seguridad en él.

En esa lucha destructiva, cada facción laboral rival buscaba la ayuda de las autoridades federales, quejándose de obstruccionismo estatal y local. También pedían su intervención lamentando la inactividad federal al respecto. El ex presidente Emilio Portes Gil, en aquel momento procurador general de la nación y también el politico tamaulipeco más importante, llegó a ser el centro de las recriminaciones de una de las facciones. ${ }^{43}$ La disputa interna de El Águila era parte de un faccionalismo más amplio entre dirigentes locales que dividió a las fuerzas laborales de Tampico. En 1933, en una convención local se dio parte a la policía, la cual expulsó a catorce delegaciones laborales pasando por alto a las autoridades municipales. ${ }^{44} \mathrm{~A}$ medida que México fue saliendo de la Depresión, entre los funcionarios locales y estatales se dio el mismo tipo de realineamientos políticos que entre los dirigentes laborales.

42 Leobardo Castellanos al Presidente, 14 agosto 1933, FAR, 334.1/653.

43 Antonio D. Domínguez, 13 noviembre 1933, AGN, Particulares EPG caja 128, exp. 8-5-a; Miguel Ramos al Procurador General de Justicia del Estado, 9 noviembre 1933, FAR, 561.3/40.

${ }^{44}$ José Magro Soto al Gobernador, 30 noviembre 1933, FAR, 561.8/190.
En 1934, año de elecciones, el faccionalismo entre los obreros de Tampico se hizo obvio. El grupo dirigido por el Sindicato de Taxistas había formado la Cámara de Trabajo y rebasado el flanco de una coalición del Sindicato de Estibadores con portesgilistas locales. Con la ayuda de funcionarios locales, dicha Cámara consiguió un salario mínimo en Tampico de 3.00 pesos diarios. ${ }^{45}$ Mientras, los acontecimientos nacionales se centraron en la huelga en Minatitlán, donde los trabajadores estaban pidiendo que incluyeran en sus contratos la claúsula de exclusión. Los trabajadores llevaron a cabo en Tampico una huelga de apoyo, que abarcó un total de 8000 obreros. ${ }^{46} \mathrm{El}$ gobierno federal deseaba unificar a todos los trabajadores de Tampico y de todo el país. Los inspectores laborales federales pidieron a los dirigentes sindicales del puerto que colaboraran en la elección de un representante a la Junta Federal de Conciliación local, constituida portres miembros. El capital y el Estado iban también a proporcionar uno, en un intento de "equilibrar" los elementos "antagónicos" del trabajo y del capital. La mediación federal no logró mucho. La Cámara del Trabajo forzó a una segunda elección cuando el primer ganador no fue de su agrado. Como miembro prominente de la Cámara, el sindicato de la refine. ría insurgente, El Águila, conquistó la

45 Macy a Sec. of State, 29 diciembre 1933, 30 abril 1934, RG 59, 812.00-Tamaulipas/134 y / 145.

46 Thomas D. Bowman, "El Águila and other strike movements in Mexico during may", 11 junio 1934, RG 59, 812.5045/168. 
suficiente alianza política para sobrevivir a las luchas internas entre facciones. Otros sindicatos de la refinería de Tampico, como la Huasteca Petroleum Co. y la Pierce/Sinclair, también pertenecían a la Cámara. La cooperación entre los poderosos sindicatos locales hizo posible que cada uno mantuviera el control de sus propios miembros en Tampico, sobre todo durante la inquieta época de la post-Depresión. ${ }^{47}$ La lucha laboral corría desde los talleres hasta los niveles local y estatal y, eventualmente, hasta el nacional.

Los trabajadores de la Huasteca Petroleum Co. (desde 1932 propiedad de la Standard Oil Co. de New Jersey) tal vez fueran más del tipo de los trabajadores de otras compañías más pequeñas. Toda su lucha laboral se centraba en resistir despidos y excedencias debidos a pérdida de producción, aumento de eficiencia y disminución de negocios. Fundada originalmente por Edward L. Doheny, la Huasteca Petroleum Co. había estado en lenta decadencia desde 1921. La compañía había despedido a cientos de trabajadores durante la depresión de 1921, después de la huelga de 1925 y, de nuevo, cuando reconstruyó su refinería en Tampico en 1930. A diferencia de El Águila, la Huasteca Petroleum Co. no había descubierto ningún nuevo campo petrolero desde 1920. Debido a fricciones, la compañía había podido mantener al sindicato relativamente débil en su planta de refinación de

47 "JFC en Tampico: Convocatoria para elección de representantes obreros y patronales", 1934, DAT, caja 20, exp. 3.
Mata Redonda, en Tampico, al otro lado del río Pánuco. Por esta razón, los representantes de los trabajadores de. pendían de la asistencia del gobierno y de sus compañeros sindicalistas de Tampico. La Cámara del Trabajo escribió al presidente Rodríguez en 1934:

Solicitan su influencia para que sea favorable el laudo, al Sindicato Único de Obreros y Empleados de la Huasteca Petroleum Co. èn la demanda que tiene ante la Junta Federal de Conciliación y Arbitraje contra la Huasteca Petroleum Co., en el caso de la separación injustificada de los CC. J. Castellanos y J. Larios. Los compañeros Larios y Castellanos son los únicos sindicalizados en sus respectivos departamentos además de los que tienen mayor antigüedad, y han sido sustituidos por trabajadores nuevos. [Siguen más apreciaciones sobre el injustificado movimiento de reajustes de la empresa]. ${ }^{48}$

En 1934, el Sindicato Único presentó a la compañía un nuevo contrato colectivo basado en el acuerdo de Minatitlán. Este sindicato pedía la claúsula de exclusión para él y para el sindicato del campo petrolero El Ébano, además de indemnizaciones por cese para 93 trabajadores de tiempo parcial despedidos por la Huasteca Petroleum Co. 49

El Sindicato Único dio su gran golpe en 1935, enfrentándose tanto a la Huasteca Petroleum Co., como a los trabajadores libres. La huelga empezó el 23 de enero e involucró a 600 hombres

48 Francisco Dávila al Presidente, 9 julio 1934 , FAR, 561.6/196.

${ }_{49}$ Littel, "Strike movements", 10 diciembre 1934, RG 59, 812.5045/184. 
de la refinería y de la terminal de la Huasteca Petroleum Co. por varios meses. Dicho sindicato ofreció regresar al trabajo si la compañía accedía al arbitraje del presidente Cárdenas. La Huasteca Petroleum Co. no lo aceptó y la huelga siguió a lo largo de todo abril, agotando sus fondos de huelga y los de sus sindicatos hermanos de Tampico. La Junta Federal de Conciliación y Arbitraje (JFCA) había declarado legal la huelga de acuerdo con las leyes laborales mexicanas. La Huasteca Petroleum Co. pidió amparo de inmediato y la Suprema Corte invirtió la decision de la JFCA. La decisión suprema significaba que, según la ley, la Huasteca Petroleum Co. no necesitaba tratar con el Sindicato Único ni reembolsar a sus miembros los salarios caídos durante la huelga. El sindicato apeló solicitando la intervencion directa del presidente Cárdenas. ${ }^{50}$

Los administadores de la Huasteca Petroleum Co. adoptaron una línea muy dura contra los trabajadores organizados. "Preferían mantener la refinería de Tampico cerrada permanentemente -dijo un diplomático estadunidense- antes que llegar a un acuerdo con los trabajadores, que han ido ocho veces a la huelga en los últimos doce meses". ${ }^{51}$ Una confrontación en la refinería, entre trabajadores libres y sindicalizados, tuvo por resultado la muerte de un trabajador libre y otro herido. Finalmente, los trabajadores

${ }^{50}$ Macy a Sec. of State, 30 abril 1935, RG 59, 812.00-Tamaulipas/187; doc. dtd. 1 marzo, 11 abril y 18 octubre 1935, FLC 432.2/2.

${ }_{51} \mathrm{R}$. Henry Norweb a Sec. of State, 26 abril 1935, RG 59, 812.45/212. libres solicitaron protección militar al gobierno, pero los funcionarios federales no estaban dispuestos a concederla porque el Sindicato Único podría considerarlo una agresión. ${ }^{52}$ La huelga fracasó a fines de noviembre de 1935, y el fracaso del Sindicato Único en la obtención de un contrato colectivo similar al del sindicato de la refinería de El Águila enconó a los dirigentes; cooperaron entonces con sus hermanos de la refinería de El Águila, más grande, tratando de formar un sindicato petrolero nacional, el cual no estaban en condiciones de liderar.

La lucha para formar el sindicato nacional de los trabajadores petroleros intensificó aún más la fuerza de los sindicatos de la refinería de Tampico. Aparentemente, la idea se había originado en Puerto México y había seducido a una serie de pequeños sindicatos de los campos petroleros que se unieron en el intento de formar el Sindicato Nacional de la Industria Petrolera y sus Derivados. Pero tanto los trabajadores de Tampico como los de la refinería de Minatitlán consideraron que este tentativo sindicato petrolero nacional era una provocación. Basándose en su mayor número de miembros y en su importancia para la industria, esos sindicatos de refinería querían ser los organizadores de tal sindicato nacional o no tener ninguno. ${ }^{53}$ Cuando algunos grupos de estos pequeños

52 Docs. dtd, 20 julio y 5 y 8 octubre 1935 FLC $432.2 / 2$.

53 Macy a Sec. of State, 29 junio 1934, RG 59, 812.00-Tamaulipas/152; Agustín Haro al Sindicato de Obreros, 9 junio 1934, DAT, caja 28, exp. 1, f. 398. 
sindicatos se reunieron en la ciudad de México, en julio de 1935, los sindicatos de refinería y sus organizaiones laborales de apoyo de todo el país, los acusaron de ser "sindicatos blancos" (sindicatos manejados por la compañía) y pidieron a los funcionarios del gobierno que les negaran su apoyo. ${ }^{54}$ El Sindicato Nacional falló en hacer viable un sindicato nacional de trabajadores petroleros.

Evidentemente, 1935 fue un año crítico para la cooperación entre los grandes sindicatos de refinería dentro de la industria petrolera. Estos sindicatos se comunicaban desde Minatitlán, Azcapotzalco, Ciudad Madero y Mata Redonda, desatando con frecuencia movimientos de adhesión, entre ellos y sosteniendo a los pequeños grupos de los campos petroleros que los apoyaban a su vez. También podían contar con otros sindicatos aliados en Tampico, en especial el agresivo Sindicato de choferes, miembro influyente de la Cámara de Trabajo. El Sindicatode Obreros de Tampico había incluido en su membrecía a trabajadores de varios campos petroleros de El Águila en el norte de Veracruz. Contaba con miembros en Pánuco, Naranjos, la terminal de carga de Tuxpan y el nuevo campo petrolero de Poza Rica. En 1935, estallaron numerosas huelgas dentro de esta industria intentado igualar pagos y prestaciones entre refinerias y campos petroleros. El presidente Cárdenas dijo, hablando de la racha de huelgas en la industria petrolera y otras,

${ }^{54}$ Extractos 14 y 16 agosto y 3 septiembre 1935, FLC 437.1/37. que eran "una simple manifestación del estado de injusticia en el que ciertas compañías mantenían a los trabajadores". ${ }^{55}$ Pero más tarde, cuando se formó el sindicato nacional petrolero, el presidente no las juzgó con tanta tolerancia.

Entre tanto, la creciente tensión política entre el presidente Cárdenas y el ex presidente Calles tuvo resonancias en todo el país y obviamente en las ciudades industriales como Tampico. La Cámara del Trabajo se alió con el ala izquierda del Senado de la república y con el general Francisco Múgica. Este grupo patrocinó la "acción directa" contra los defensores locales del gobernador de Tamaulipas, que era un aliado de Portes Gil. Las multitudes invadieron la Cámara del Consejo del puerto y las salas de redacción de los periódicos locales. Corría el rumor de que dicha Cámara también quería depurar a la dirigencia de la Unión de Alijadores, el sindicato más antiguo de Tampico -databa de 1911- incitando a una toma multitudinaria de la sede de los trabajadores portuarios. EI desfile de febrero de 1936, en apoyo al alcalde de Tampico, que acababa de ser destituido por el gobernador, proporcionó la ocasión. Al final del desfile hubo disparos y una multitud furiosa atacó el edificio de la Unión de Alijadores. La policía local y las autoridades militares, o no estaban preparadas para intervenir o, en realidad, estaban a favor de la Cámara, pues no hicieron nada para detener la revuelta. Al final

55 Docs. dtd. 11, 15 y 27 enero 1935, FLC 433.2/8; John S. Littel, "Strike movements", 4 febrero 1935, RG 59, 812.45/191. 
del día, tres miembros del grupo de trabajadores portuarios habían sido muertos y trece heridos, en comparación con un atacante muerto y cuatro heridos entre los atacantes. 56

Cuando Calles se vio obligado a exilarse, los planes para la formación de un sindicato nacional petrolero se solidificaron emergiendo los sindicatos de refinería en primer plano. El grupo de la refinería El Águila cambió su nombre por el de Sección 1 del Sindicato de Trabajadores Petroleros de la República Mexicana (STPRM). El sindicato de la refinería Huasteca Petroleum Co. se convirtió en la sección 2 . Lombardo Toledano, que acababa de organizar la CTM, fue a hacer la corte a los dirigentes laborales de Tampico a puerta cerrada. Los dirigentes de los sindicatos de la refinería local se negaron entonces a hacer públicas sus intenciones de incorporarse a la CTM. Varios sindicatos petroleros pequeños aún se oponían al STPRM. Los trabajadores de la compañía La Corona en Pánuco permanecieron leales a la CROM. Los trabajadores de Petro-Mex y Gulf Petroleum Co. no tenían ningún sindicato. ${ }^{57}$

El acrecentamiento del poder de los trabajadores de la refinería El Águila en Tampico, no se logró sin producir algo de descontento, o envidia. Representantes de los trabajadores de campo de Tuxpan y Papantla protestaron porque los dirigentes de la sección 1 los excluyeron de sus conver-

${ }^{56}$ Macy a Sec. of State, 13 febrero 1936, RG 59, 812.00-Tamaulipas/253.

${ }^{57}$ Doc. dtd., 30 abril 1936, FLC 432.3/191; Macy a Sec. of State, 30 septiembre 1936, RG 59, 812.00/-TAMAULIPAS/282. saciones con la compañia. A otros, pertenecientes incluso a la propia refinería de Tampico, les disgustó ser calificados de "renegados" y excluidos de contratos laborales por no comulgar con las ideas de los dirigentes de la sección $1 .{ }^{58}$ Por el hecho de reunir el conglomerado mayor de trabajadores $-6500-$, el sindicato de la refinería El Águila fungió también de vanguardia en la formación del sindicato nacional petrolero. Los dirigentes de este sindicato buscaron más tarde la confirmación de su poder a través de un contrato laboral que alcanzara a toda la industria.

\section{LA LUCHA POR UN CONTRATO NACIONAL}

La formación del STPRM en 1936, no fue, como hemos visto, el comienzo de la lucha de los trabajadores para controlar su lugar de trabajo. Esta lucha en contra de los despidos y por la estabilidad en sus vidas, había comen. zado desde 1915 , si no es que antes y se intensificó a causa de los despidos ocurridos durante la Depresión. Por lo tanto, la formación del STPRM no era sino otra etapa de la misma lucha. La formación de un sindicato dentro de la industria petrolera elevó el nivel de ese combate que se extendió desde las refinerías y los campos petroleros hasta la política nacional e internacional. Pero ello no significaba que la militancia de base estuviera superada, por el contrario, continuaban las luchas

58 Extractos 8, 10 y 25 enero y 20 octubre 1936, FLC 432.3/170. 
locales por el liderazgo y la adhesión de los trabajadores, a fin de mantener una incesante presión sobre los dirigentes laborales nacionales y políticos y lograr que apoyaran la seguridad de los trabajadores petroleros. Los dirigentes del STPRM y de la CTM sabían que si no satisfacían las demandas que venían de abajo, sus pretensiones de poder y percepciones por llevar el timón del sindicato eran inútiles. No cabe duda de que el presidente Cárdenas sintió estas mismas presiones.

Mas los extranjeros, incluso los petroleros, creían en aquel momento que el radicalismo laboral mexicano empezaba en la cúspide. Como telegrafió un diplomático británico comisionado en la ciudad de México durante la confrontacion decisiva entre Cárdenas y Calles:

El actual gobierno parece creer que la garantía más segura contra el regreso del régimen de Calles es la de organizar a la fuerza de trabajo en su apoyo. La pandilla de Calles, por otra parte, siempre ha tratado de embarazar a sus sucesores promoviendo la agitación laboral. La fuerza de trabajo es por lo tanto la herramienta de los grupos políticos en contienda y es llevada por ambos bandos a descaradas extravagancias. ${ }^{59}$

Pero como lo indica este análisis de los trabajadores petroleros, la militancia sindical surgió en los talleres. Sus dirigentes sabían lo que hacían.

Conscientes de que tenían que obtener una victoria para conservar la leal-

59 Murray a Foreign Office, 27 febrero 1936, FO 371-19792/A2055/196/26. tad de sus miembros, Ios dirigentes del STPRM conferenciaron incansablemente hasta proponer un contrato colectivo al alcance de toda la industria. En éste se pedía un aumento salarial de 30000000 de pesos (aproximadamen te 8300000 dólares), así como la igualación de los salarios entre las $18 \mathrm{com}$ pañías petroleras, terminales y navieras a cuyos trabajadores representaba este sindicato. ${ }^{60}$ Pedían también 18 días festivos (incluido el Día del Trabajador Petrolero), amplias prestaciones por muerte y enfermedad, de 20 a 60 días de vacaciones pagadas, viaje de vacaciones y seguridad médica completa. Asimismo que muchas de estas prestaciones incluyeran a las familias además de al trabajador. Si un hombre dejaba el trabajo, obtendría 25 días de pago por cada año de labor. Si se le despedía, 90 días de pago más 25 días de indemnización por cada año de servicio a la compañía. En todos los casos, los trabajadores despedidos no perderían los derechos de antigüedad y tendrían preferencia en la recontratación.

Estas y otras disposiciones del contrato propuesto preveían una amplia participación de los trabajadores en la administración. Todas las obligaciones y gastos del contrato estarían a cargo de las compañías. Mucho del poder de decisión sobre asuntos de personal lo iban a asumir los dirigentes del STPRM. La compañía habría tenido que pagar el transporte, equipo y uniformes de

60 Véase "Proyecto aprobado en la primera Gran Convención Extraordinaria del Sindicato de Trabajadores Petroleros de la República Mexicana", sin fecha, AHH, caja 1857-117. 
los grupos musicales del sindicato, coches para los dirigentes sindicales y una casa para cada trabajador. Las compañias tendrían que proporcionar escuelas, bibliotecas, fondos de ahorro y clubes de deporte que serían dirigidos por los sindicatos. Los dirigentes sindicales tendrían que tratar con los administradores de personal de la compañía, todas las promociones. Ellos dirigirían las escuelas técnicas, a cargo económicamente de las compañías, las cuales capacitarían a los técnicos mexicanos que sustituirían a los extranjeros. Las compañías pagarían a los oficinistas de las propias oficinas del STPRM y deducirían automáticamente las cuotas sindicales del cheque de cada trabajador. Además, también los salarios de los funcionarios del STPRM deberían pagarlos las compañías.

El contrato tocaba los privilegios del empleador en cuanto a los puestos de confianza y el derecho a contratar y despedir. Los puestos de confianza habían quedado tradicionalmente fuera del control sindical. Ahora el STPRM pedía que quedaran reducidos a 110 en toda la industria petrolera mexicana. El Águila conservaría sólo un puesto de confianza (entonces tenía trece) en su refinería de Azcapotzalco, el del gerente general. ${ }^{61}$ Todos los otros puestos de supervisión serían ocupados por miembros del sindicato, máso menos según una estricta base de antigüedad. Sobre todo, gran parte del poder de contratar y despedir obreros le era suprimido a la compañía y pasaba f. 25.

61 Doc. dtd., 1 julio 1937, AHH, caja 1844-3, al sindicato, esto era una implicación última de la claúsula de exclusión. "Las compañías se obligan a suspender a los trabajadores que el Sindicato acuerde disciplinar", decía el contrato propuesto, "y por todo el tiempo que la disciplina dure: sin que las compañías tengan que calificar la procedencia o improcedencia de tales disciplinas." ${ }^{2}$ Si la facultad de castigar y recompensar eran los pilares gemelos del poder social, entonces los dirigentes sindicales petroleros tenían plenas expectativas de arrebatar ese poder a las compañías. Se proponían hacerlo mediante el contrato laboral propuesto referido a toda la industria en 1936.

El STPRM entregó el contrato a las compañías el 3 de noviembre de 1936 pidiendo su aprobación para antes del 17 de noviembre, fin del plazo de huelga. La respuesta de las compañías era predecible. "El proyecto del sindicato contiene más de 250 cláusulas, en 165 páginas, tamaño legal, de las que casi 40 abarcan el programa salarial y tomó varios meses formularlo", contestaron. "Y así, las compañías tienen que 'discutir' y 'aprobar' el documento en el periodo perentorio de diez (10) días." 63 Las compañías pequeñas se declararon en desacuerdo con la nivelación porque no podían

62 "Proyecto aprobado en la primera Gran Convención Extraordinaria", AHH, caja 1857. 117, f. 422.

63 "The mexican oil strike of 1937 ", 2 vols., México, sin fecha, vol. I, p. 3. Véanse las objeciones adicionales de la compañía en Macy, "Proposed collective labor agreement", 21 mayo 1936, RG 59, 812.00-Tamaulipas/421. 


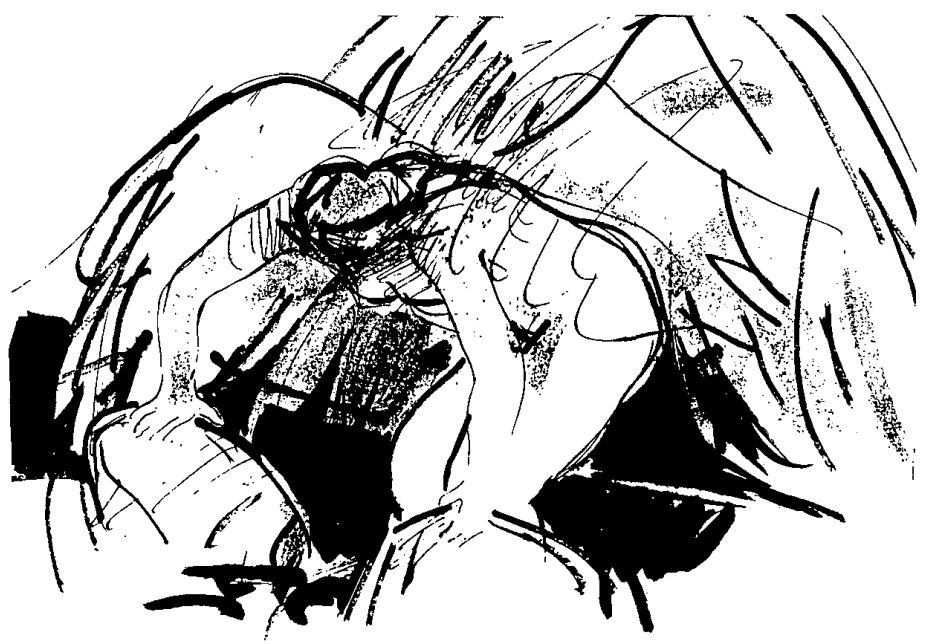

pagar los altos salarios que El Águila y la Huasteca Petroleum Co. pagaban a sus obreros. Estas dos grandes compañías, también se resistieron en principio, a subir los salarios de unos trabajadores que eran los mejor pagados del país. $Y$ aunque ejecutivos y dirigentes laborales por igual formulaban sus pronunciamientos públicos en términos de salarios, el tema salarial estaba en realidad subordinado al del control obrero.

La propuesta de contrato de 1936 hubiera erosionado la flexibilidad del capital para competir en el mercado. Los esfuerzos laborales por sindicalizar incluso a los trabajadores eventuales y de tiempo parcial ocasionarían que las compañías ya no pudieran contratar fuerza de trabajo temporal para pro- yectos especiales. Y si lo hacían, no podrían dejar libres a los trabajadores cuando hubieran terminado el trabajo. El contrato de 1936 también hubiera marcado el fin del trabajo contractual dentro de la industria. Las compañías dependían de concesionarios de construcción y perforación para realizar trabajos ad hoc, y para los cuales la agencia contratante aportaba sus propios trabajadores. Además, las compañías objetaban que iban a encontrar dificultades para despedir a trabajadores incompetentes o ineptos. Un trabajador sólo podía ser despedido por causas "graves e ignominiosas", causas que iba a revisar un grupo integrado por el sindicato y la administración. Las compañías dijeron que, según el contrato de 1936, ellas hubieran per- 
dido todos los derechos de transferencia o promoción de sus empleados.

Como las compañías no podían aceptar esas condiciones para el nue vo contrato, parecía inevitable una huelga en toda la industria. Este tipo de huelga hubiera alterado el tránsito urbano, la generación de energía, la producción industrial y las cosechas agrícolas en todo el país. Amenazaba además con desatar agitación laboral adicional en otros sectores. Por lo tanto, el presidente Cárdenas intervino para convencer a los obreros y los patronos de que discutieran el contrato $y$ de que los trabajadores petroleros permanecieran entre tanto en sus puestos. El Estado actuó como anfitrión y moderador de la disputa. Las pláticas formales entre los dirigentes del STPRM y los abogados de la industria se celebraron en el Departamento de Trabajo y en presencia de su jefe, Genaro V. Vásquez. Las compañías también querian estabilidad laboral durante un largo periodo de tiempo, pero no a costa de perder el control obrero. Además, cada compañía necesitaba aprobar el acuerdo final. Por su parte, el STPRM tenía que entregar un contrato que fuera mejor que cualquier otro existente o enfrentar la insatisfacción de sus bases. ${ }^{64}$ El hiato entre las posiciones de los trabajadores y los patronos parecía insuperable y, en efecto, lo era.

Los dirigentes sindicales que asistieron a las negociaciones pronto se cansaron de la meticulosidad de los

${ }^{64}$ Veánse las transcripciones de las sesiones dtd. 26 noviembre y 12 diciembre 1936, AHH, caja 1858-119, ff. 36, 79, 102. abogados de la compañia. "No es la primera vez que no nos hemos podido entender con los licenciados Guerrero y White", comentó un veterano dirigente laboral. "Con los patrones, que son los directamente interesados, hemos podido ponernos de acuerdo mejor que con ellos. Cada vez que hemos tratado con los patrones hemos llegado a un fin práctico." 65 El jefe de la CTM, Lombardo Toledano, que también era un licenciado, asistió a las sesiones finales. Habló con elocuencia en favor de la necesidad de establecer la seguridad individual del trabajador. Lombardo pidió que "el trabajador que pierde su empleo tenga siquiera una pequeña cantidad de dinero que le permita buscar fortuna en un país como el nuestro, donde por desgracia también no abunda el trabajo". ${ }^{66}$ Estas conversaciones laborales patrocinadas por el Estado se rompieron a finales de mayo de 1937.

El presidente Cárdenas intervino una segunda vez, después de una huelga petrolera nacional, consiguiendo que los sindicatos aceptaran el estudio económico de las compañías petroleras. Como se estipulaba en la ley laboral de 1931, las investigaciones económicas determinarían si las compañías podían permitirse o no el contrato propuesto. El profesor Jesús Silva Herzog, maestro de la UNAM, encabezó un equipo de tres expertos que constituirían la Comisión Pericial en el conflicto de orden económico de la in-

65 Doc. dtd., 15 diciembre 1936, АHH, caja 1858-119, ff. $259-260$.

66 Doc. dtd., 24 mayo 1937, AHH, caja 1858 119, f. 1645 . 
dustria petrolera. Durante los meses de junio y julio de 1937, Silva Herzog reunió estadísticas, testimonios y pruebas sobre impuestos, ganancias, gastos y salarios. Las compañías dijeron a esta Comisión que la minuta laboral era mucho más alta que los aumentos de salarios indicados. El Águila calculó que el contrato aumentaría sus costos laborales en 142600000 pesos al año. ${ }^{67}$ Trabajando bajo presión, el estudio de la Comisión se presentó al público el 14 de agosto. Asumía la forma de recomendaciones a la Junta Federal de Conciliación y Arbitraje (JFCA), la cual iba a solucionar la disputa laboral que las compañías y los dirigentes sindicales habían sido incapaces de negociar. Las deliberaciones de la JFCA prosiguieron durante el resto de 1937. El 3 de marzo, ésta confirmó finalmente las averiguaciones de la Comisión, concediendo a los trabajadores un aumento salarial de 26400000 pesos y a los dirigentes laborales muchas de sus demandas administrativas. Las compañias pidieron un amparo contra el dictamen de la JFCA, pero la Suprema Corte de Justicia de México, que se había reconstituido a fondo durante el sexenio de Cárdenas, corroboró la resolución de la JFCA el 2 de marzo de 1938. De hecho, el Estado estaba tratando de resolver el conflicto que patronos y dirigentes laborales no podían resolver.

Pero las compañías aún se negaban a acatar la decisión. Los petroleros extranjeros habían estado diciendo que

67 Doc. dtd., 24 junio 1937, AHH, caja 18443-bis, legajo 1, f. 19. la demanda de aumentos salariales y participación en la gestión del sindicato, haría que se fueran a la bancarrota las compañías con base en México, ya bastante improductivas. "Debidoal actual número restringido de puestos de supervisión" -reclamaron en diciembre de 1937-, "la industria ya está sufriendo las consecuencias de la falta de control y disciplina." ${ }^{88}$ Si la agitación laboral hacía que el petróleo mexicano fuera más caro, advertían, se iba a malvender en los mercados extranjeros por la competencia de los crudos venezolanos más baratos. En consecuencia, el gobierno mexicano perdería ingresos en cuanto a exportación petrolera. Además, las companías no creían que los mexicanos pudieran manejar la industria petrolera por sí solos. Por tanto, plantearon un reto al presidente Cárdenas: disciplinar a los trabajadores por ellas. Las compañías simplemente se negaban así a operar en México bajo las condiciones laborales acordadas por el sistema político mexicano.

Por ello, los ejecutivos de las compañías y algunos diplomáticos extranjeros creyeron que la final nacionalización de la industria petrolera fue una confabulación de Cárdenas. Éste utilizó la fuerza de trabajo sólo como un rastro, una diversión y una trampa, estuvieron prontos a afirmar. Naturalmente, las motivaciones del presidente siguen siendo, en cierto modo, enigmáticas. Ya en 1935, el embajador británico lo citaba hablando en tono meditativo sobre la "ventaja que

68 "The mexican oil strike", vol. II, p. 25. 
resultaría para la nación del control directo del Estado [...] sobre algunas de las industrias básicas, como [...] la producción de combustible". Un segundo diplomático citaba a Cárdenas, dos años después, insinuando "que no está lejos el momento en que México estará maduro para la nacionaliza. ción de la industria petrolera" ${ }^{69}{ }^{\circ}$ Pero era ésta su meta a largo plazo? Ambas observaciones, hechas tal vez con la intención de que llegaran a oídos de los administradores petroleros para impulsarlos a un acuerdo con sus trabajadores, habían sido hechas por el presidente durante algunas refriegas laborales en los campos petroleros. Cárdenas había vislumbrado tal vez la nacionalización del petróleo como un medio para suavizar las demandas de los obreros.

No obstante, sus acciones contradecían tal política de conciliación entre las compañías y los trabajadores. Había sido idea suya, primero, forzar a los trabajadores a que entraran en conversaciones directas con los patronos; después, pedir que se realizara una investigación económica; luego esperar el fallo de la JFCA y, por último, aguardar la resolución de la Suprema Corte a la apelación. Aun después de que la Suprema Corte dio su fallo, Cárdenas pidió a los trabajadores que dieran tiempo a las compañías para acatarla.

${ }^{69}$ Murray a Foreign Office, 20 abril 1935 , Gallop a Foreign Office, 3 junio 1937, fo 371. $18710 /$ A4432/1455/26 y FO 371-20639/A4243/ $527 / 26$. Para una discusión más amplia de los motivos de Cárdenas, véase Alan Knight, "The politics of expropiation", manuscrito, The University of Texas, 1988.
Sólo entonces entró en sus planes la posibilidad real de la nacionalización. Le confió a Múgica que si las compa. ñías se resistían a la resolución de la Suprema Corte no iba a tener más alternativa que expropiar. ${ }^{70}$

Hay que dejar algo en claro: Cárdenas no necesitaba expropiar la industria para defender el artículo 27 de la Constitución. En diciembre de 1937, Cárdenas y El Águila firmaron un acuerdo en el que la compañía petrolera parecía renunciar a sus derechos de propiedad del nuevo campo petrolero de Poza Rica. La compañía británica accedió a ser allí "concesionaria" pagando regalías al gobierno del 25 al $35 \%$ del valor de la producción. Esto significaba que, una compañía extranjera había reconocido tácitamente el derecho del gobierno sobre su explotación petrolera, como estaba estipulado en la Constitución mexicana. ${ }^{71}$ Cárdenas abrigaba la esperanza que, con el tiempo, las demás compañías petroleras llegaran a aceptar estas disposiciones constitucionales. A fin de cuentas, el artículo 27 de la Constitución no contenía el mandato de hacer un monopolio de la explotación del petróleo, sino el de establecer el derecho de la nación sobre el subsuelo. Los constituyentes habían considerado que las compañias privadas podrían explotar-

${ }^{70}$ Lázaro Cárdenas, Obras, 1972, 3 vols., vol. I, p. 389.

71 "Convenio que celebran...", 11 noviembre, Daniels a Sec. of State, 17 noviembre 1937, RG 59, 812.6363/3064 y /3042. Sobre las espectativas de Cárdenas del contrato de El Águila, véase Daniels a Sec. of State, 22 marzo 1938, RG 59, 812.6363/3101. 
lo bajo contrato con el gobierno, pues entidades privadas ya se habían beneficiado antes de los depósitos de plata, pagando regalías a la corona quien formalmente era dueña de la riqueza del subsuelo. El compromiso de Poza Rica era simplemente un acuerdo de este tipo. Las circunstancias dictaron que los trabajadores, movidos por sus propios intereses, dieran otro significado al artículo 27 .

PRESIÓN DE LOS TRABAJADORES

PETROLEROS AL ESTADO

Los trabajadores y sus dirigentes siempre habían apelado al Estado para que atendiera sus quejas. Los trabajadores petroleros llevaron estas tradiciones hasta adentrado el siglo Xx. Se comunicaron directamente con el presidente, con las agencias nacionales adecuadas y con las facciones políticas estatales y locales. También calcularon su actividad huelguística para obtener la intervención del Estado en sus asuntos, preferiblemente en su favor. La actividad política llegó a ser especialmente decisiva para los trabajadores petroleros. Estaban luchando por preservar para sí mismos puestos fijos en una industria famosa por sus bienes privilegiados. Shell y Standard Oil New Jersey, que controlaban El Águila y la Huasteca Petroleum Co., respectivamente, secontaban entre las empresas industriales más grandes del mundo. Parte de su poder económico se debía a su capacidad para nivelar la producción y el empleo a escala internacional. Después de todo tenían que sobrevivir en un mercado petrolero mundial volátil y competitivo. El poder de las compañías no desalentó a los trabajadores, pero hizo que la intervención estatal fuera mucho más crucial para el logro de sus metas. Si los trabajadores querían ganar alguna seguridad en la industria, necesitaban líderesfuertes que pudieran negociar exitosamente con los políticos. Cuando el gobierno vaciló, los trabajadores fueron capaces de apremiarlo y cuando sus propios dirigentes sindicales titubearon, los trabajadores supieron también cómo aguijonearlos.

A partir del momento en que el contrato nacional fue entregado a las compañías, los trabajadores petroleros ejercieron presión directa e inexorable sobre todas las partes. La huelga fue su arma. En el momento en que el STPRM terminó su proyecto del contrato a proponer, en noviembre de 1936 , los trabajadores de El Águila de Tampico regresaron al trabajo después de 23 días de huelga. Sus colegas de la refinería cercana de la Pierce-Sinclair pusieron también fin a una huelga de 56 dias. $^{72}$ Ciertamente, el faccionalismo laboral no terminó cuando el STPRM entró en negociaciones a nivel nacional. Las conversaciones laborales tuvieron que ser suspendidas en enero de 1937, para que la Sección 1 pudiera tratar con los sindicatos de estibadores, quién iba a controlar la descarga de buques petroleros en Tampico. Después, cuando los patronos se mostraron reacios a reanudar las conversacio-

72 Macy a Sec. of State, 30 noviembre 1936, RG 59, 812.00-Tamaulipas/287. 
nes nacionales, la Sección 1 ordenó un paro laboral de un día. ${ }^{73}$

La principal huelga petrolera empezó a fines de junio de 1937 , a consecuencia de la ruptura de las conversaciones administración-trabajo. Todas las compañías excepto la Mexican Gulf y la Petro-Mex (que no tenían sindicatos) tuvieron que suspender las operaciones. Los tanqueros tuvieron que abandonar Tampico sin sus cargamentos usuales, y los buques de carga no podían conseguir combustible en ninguno de los puertos de la costa mexicana del Golfo. Las ciudades portuarias sufrieron pérdidas en cuanto a tarifas, y el gobierno federal, en cuanto a derechos aduanales. ${ }^{74}$ En una semana, la huelga produjo hostilidades en la ciudad de México. Los trabajadores petroleros colocaron las banderas rojinegras de huelga en los depósitos de Petro-Mex, porque la compañía estatal estaba vendiendo combustible a turistas y a las compañías comerciales. Los taxistas y camioneros estaban molestos porque el gobierno favorecía a los choferes de autobús en la distribución de gasolina racionada. Bloquearon varias vías públicas importantes de la ciudad. Por último, Cárdenas intervino directamente, consiguiendoque los trabajadores suspendieran la huelga petrolera después de trece días a cambio de una investigación económica de las compañías. ${ }^{75}$

${ }^{73} \mathrm{~S}$. Roger Tyler, Jr., "Developments in petroleum labor code in Mexico", 15 enero 1937, RG 59, 812.504/1635.

74 Jack D. Neal a Sec. of State, 1 junio 1937 , RG 59, 812.000-Tamaulipas $/ 310$.

75 Pierre de L. Boal a Sec. of State, 5,7 y 9
A los trabajadores petroleros de base les disgustó este compromiso e iniciaron una serie de "huelgas ilegales", paros laborales descoordinados de corta duración. Varios miembros de la delegación del STPRM, cuya huegla había finalizado por insistencia del presidente Cárdenas, fueron expulsados de sus cargos cuando regresaron a sus oficinas. Los trabajadores de tiempo parcial, del campo petrolero de la Huasteca Petroleum Co., en Cerro Azul, faltaron al respeto a cuatro funcionarios de la compañía, dos de los cuales eran mexicanos. Estos trabajadores hubieran sido de tiempo completo si la compañía hubiera firmado el nuevo contrato. "Los trabajadores parecen tener la sensación de que los dirigentes sindicales no respaldaron adecuadamente en México sus demandas -informó un diplomático estadunidense en Tampico-, y que, en consecuencia, tienen que actuar por sí mismos." ${ }^{76}$ Estas huelgas, aunque ilegales, ${ }^{77}$ tenían la intención de obligar a la Comisión Pericial a presentar un informe favorable. Desde Yucatán, donde estaba repartiendo tierra a los campesinos, el presidente Cárdenas telegrafió pidiendo que cesaran dichas huelgas, pero no muchos trabajadores

junio 1937 , RG $59,812.45 / 397, / 409$ y $/ 402$; El Águila a Anglo-Mex, 2 junio 1937, Fo 371-20639/ A4049/132/26.

76 Tyler, "End of petroleum strike in Mexico", 11 junio 1937, L.S. Armstrong, "Resume of events in the oil industry", 16 junio 1937, RG 59, 812.45/ 419,424 ; Joseph Pyke a Foreign Office, 18 junio 1937, Fo 371-20639/A4795/527/26.

77 Gallop a Foreign Office, fo 371/20639/ A6194/527/26; Boal a Sec. of State, 10 agosto 1937, RG 59, 812.45/495. 
petroleros prestaron atención a su llamado.

Aún existía animosidad en la refinería de la Huasteca Petroleum Co. y en la terminal de Mata Redonda. La Sección 2 se declaró en huelga una serie de veces en septiembre y octubre de 1937 buscando su propio contrato local en vez de un contrato nacional. La agitación laboral continuó intermitentemente en noviembre y diciembre. Varios de los paros laborales de diciembre indicaron la frustración de los grupos locales por la duración de las deliberaciones de la JFCA. Al menos ésta fue la razón de que la Sección 1 amenazara con un paro de 24 horas en la refinería El Águila de Tampico. Cárdenas expresó su desagrado en los periódicos de la nación. ${ }^{78} \mathrm{La}$ respuesta hostil de la Huasteca Petroleum Co., a la decisión de la JFCA que, en su opinión, era favorable a los trabajadores, provocó aún más el resentimiento obrero. La filial de la Standard Oil clausuró 23 pozos y ordenó que todo el petróleo almacenado en ese campo fuera trasladado a su terminal en Tampico. En su último sobre de pago, de diciembre de 1937, cada trabajador de la Huasteca Petroleum Co. recibió un mensaje comunicándole que la compañía no iba a poder dar cumplimiento a la decisión de la JFCA. Posteriormente, los dirigentes de la Sección 2 se enojaron tanto con los administra. dores de la Huasteca Petroleum Co., que éstos se mostraron decididos a

\footnotetext{
${ }^{78}$ Armstrong a Sec. of State, 1 diciembre 1937, RG 59, 812.00-Tamaulipas/328; Extracto, 9 diciembre 1937, FLC 432/87; El Universal, 10 diciembre 1937.
}

cerrar la planta mexicana de ácido de la refinería de Mata Redonda. Ellos, Borrego y Noyola, habían cerrado la terminal en Tuxpan anteriormente, en 1932. Los petroleros extranjeros habían llegado a la conclusión de que, más de 90 huelgas no autorizadas, habían infestado la industria petrolera durante los últimos seis meses de 1937.79 Las posiciones de los trabajadores y sus patronos no parecían dejar gran margen a la negociación.

Los obreros petroleros de Poza Rica cobraron fama de ser los más alborotadores de toda la industria petrolera. Mucha de la sindicalización de base había surgido en Poza Rica por problemas referidos al radio de acción. EI nuevo campo petrolero de El Águila, en expansiôn durante los años treinta, no sufrió, como la mayor parte de los lugares petroleros de trabajo, un deterioro en cuanto a trabajadores. Pero aun en estas condiciones favorables, los trabajadores competían unos con otros por el derecho al trabajo y sus organizaciones, por el de representación. A principios de los años treinta, al expandir su fuerza de trabajo en Poza Rica, la compañía británica había enviado trabajadores experimentados de Tampico. Por lo tanto, el Sindicato de Trabajadores, más tarde Sección 1 de El Águila, de la refinería de Tampico, reclamaba jurisdicción sobre Poza Rica. Residentes anteriores de la zona se sintieron menospreciados, pensando que eran ellos los que de-

79 Armstrong a Sec. of State, 4 enero 1938, RG 59, 812.00-Tamaulipas/331; Rafael Mazatán R., 9 marzo 1938, DAT, C180, E1; Daniels a Sec. of State, 20 octubre 1937, RG 59, 812.45/576. 


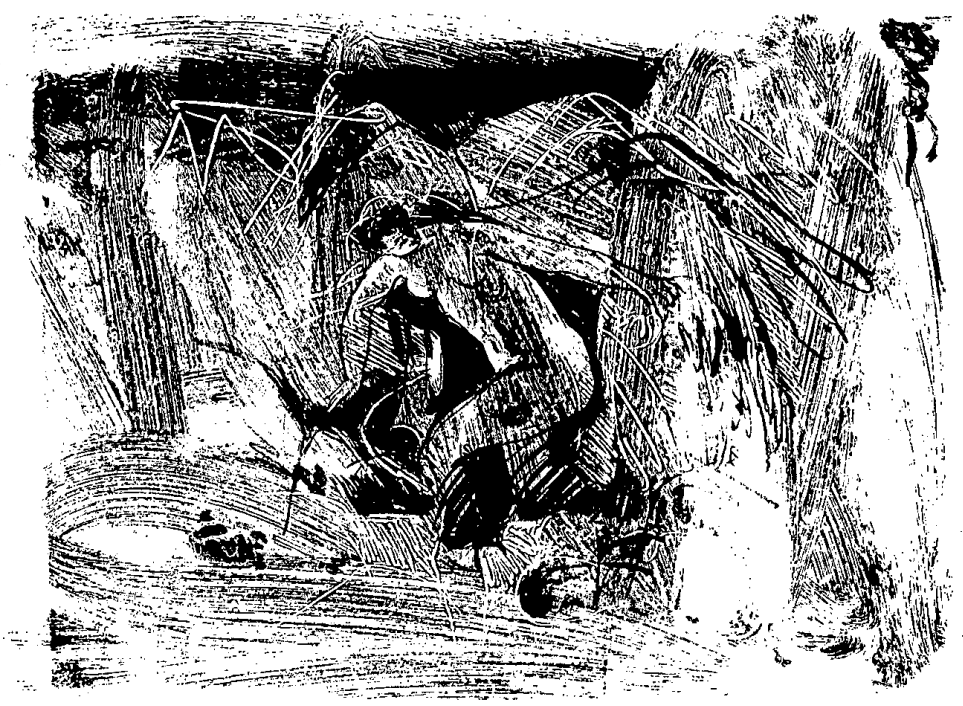

bían beneficiarse con esos puestos de trabajo. De modo que el Sindicato de Obreros y Jornaleros de la zona petrolera de los ex Cantones de Tuxpan y Papantla, dijo que hablaba en nombre de 5600 veracruzanos que resentian la invasión del sindicato de Tampico. ${ }^{80}$

Y es más, la Sección 1 usó los privilegios de su contrato colectivo conquistado en Tampico, para controlar al que fuera contratado. Rechazó a un técnico mexicano que la compañía había enviado a la escuela de ingeniería porque provenía de la refinería de Minatitlán. La Sección 1 había cobrado un enorme poder en cuanto al con226.

${ }^{80}$ Extracto, 21 septiembre 1936, FLC 432.3/ trol de los trabajadores de Poza Rica. Una huelga en este lugar repercutía en la ciudad de México, abastecida vía oleoducto desde esa ciudad, pues la capital tenía almacenado sólo el combustible para diez días en todo momento. ${ }^{81}$ La nación $-y$ los funcionarios del gobierno- podían soportar huelgas petroleras prolongadas en cualquier otro lugar, pero no en Poza Rica.

Para estos sindicalistas de campo petrolero surgió la oportunidad de separarse de la Sección 1 después de la

${ }^{81}$ H.W. Foote, "Dificultades con los sindicatos", 26 septiembre 1936, FLC 432.2/8; James Espy, "Strike situation in the petroleum industry in Mexico", 30 octubre 1936, RG 59, 812.45/ 336. 
huelga de junio, cuando el encono de los trabajadores de base por la investigación económica debilitó a algunos de los dirigentes del STPRM. En julio, Poza Rica tenía su propia representación del STPRM, Sección 30, la cual desafió al gobierno así como al comité central del sindicato petrolero nacional. Cortó el flujo de petróleo a la ciudad de México a lo largo de todo el verano y el otoño con huelgas ilegales. Otras compañías y otras instalaciones trataron de compensar la escasez de suministro a la capital, pero hubo retardos de transporte e industriales así como especulación en el abasto de combustible. ${ }^{82}$ Tan grande era el interés de las bases por la estabilidad en el empleo que el contrato que finalizó la disputa a principios de septiembre, se preocupó por nombrar trabajadores en puestos específicos y con salarios precisos. A pesar de ello, no todos quedaron satisfechos. Exasperado por las huelgas adicionales en Poza Rica, Cárdenas se sintió una vez más obligado a criticar la "falta de disciplina" de los sindicatos petroleros. Sugirió que tal vez estuvieran trabajando por "interés capitalista" en la medida en que sus tácticas estaban poniendo al país en contra del movimiento obrero. ${ }^{83}$ Los trabajadores de Poza Rica abandonaron los piquetes de huelga, no sólo porque el presidente se lo había pedido en aras del interés nacional, sino

82 Boal a Sec. of State, 25 y 26 julio 1937 , James Stewart a Sec. of State, 17 agosto 1937, RG $59,812.45 / 463, / 479, / 501$.

83 Daniels a Sec. of State, 8 septiembre 1937 , RG 59, 812.34/548; El Universal, 13 septiembre 1937. porque la compañía acordó pagar el $75 \%$ del salario de los trabajadores durante la huelga y 25000 pesos $(7000$ dólares) al sindicato. ${ }^{84}$

Una breve revisión de las actas de las asambleas de la Sección 30 , en los meses que llevaron a la expropiación petrolera, revela qué motivó y qué no motivó a las bases en Poza Rica. No hubo ninguna discusión sobre el desafio de las compañías a las resoluciones de la JFCA y de la Suprema Corte. No hubo denuncias de imperialismo extranjero ni demandas de nacionalización de la industria. Los trabajadores de los campos petroleros se involucraban más en su radio de acción. Por ello discutieron acuerdos con sindicatos hermanos sobre el derecho a trabajar los campos de las cercanías y sobre si se debía o no conceder un contrato a J. Heflye para la construcción de carreteras. También se discutieron cuestiones de membresía sindical, a veces acaloradamente, si había algún indicio de que el nuevo trabajador había colaborado alguna vez con la administración. A veces desafiaron a la dirigencia nacional del STPRM sobre estos temas. Discutieron asimismo acerca del equivalente a tres meses de cuotas sindicales que había desaparecido de la Tesorería. En cierto momento, el secretario registró: "El compañero Domingo hace uso de la palabra diciendo que el dinero es el mismo lío de siem-

84 Jack D. Neal a Sec. of State, 30 septiembre 1937, RG 59, 812.00-Tamaulipas/320. Véase también Alberto J. Olvera, "Working class culture, Union organization, and petroleum nacionalization in Poza Rica, 1932-1940", manuscrito, The University of Texas, 1988. 
pre, que no se sabe nunca, en realidad, cuánto hay en caja ni cuánto se debe." 85 Pero las bases de Poza Rica no expresaron ninguna opinión sobre la expropiación de la industria en la que laboraban; aún así, su inexorable presión sobre sus propios dirigentes sindicales llevó justo a este resultado.

Las demandas directas que los trabajadores de las refinerías y de los campos petroleros hacían a su dirigencia sindical explican por qué ésta, en febrero y marzo de 1938, se negó a hacer concesiones a las compañías. El STPRM ignoró una oferta de las mismas de elevar los salarios por un total de 23500000 pesos en vez de 26400000 pesos, como se estipulaba en la decisión de la JFCA. Esta cantidad representaba un aumento de $100 \%$ en la oferta del año anterior de la compañía. También impidieron que el gobierno participara en el contrato laboral. En el II Congreso de la CTM, de febrero de 1938, la delegación del STPRM indicó que los 5000 delegados apelaran al presidente de la Suprema Corte para pedir que los magistrados apresuraran su decisión final. ${ }^{86}$

Dado su activismo constante, los sindicatos petroleros no fueron meros espectadores de la expropiación y participaron activamente. Cuando las compañías declararon que no podían obedecer la decisión de la Suprema

85 "Acta de sesión de la Sección 30 del STPRM", 27 enero 1938, mecanografiado, 37. El autor agradece a Fabio Barbosa Cano por su ayuda con las copias de este documento.

86 O'Malley a Holman, 13 enero 1938, Fo 371-21462/A887/10/26; Daniels a Sec. of State, 25 febrero 1938, RG 59, 812.504/1720.
Corte, el STPRM convocó a una huelga que iba a empezar en la medianoche del 18 de marzo de 1938; anunció asimismo un día de protesta contra las compañias petroleras extranjeras para el 23 de marzo, mientras que la CTM prometió patrocinar una manifestación gigantesca en el Zócalo de la ciudad de México. Los propios trabajadores se anticiparon a sus dirigentes: tomaron el control de la terminal de carga de El Águila, de Tampico, y cerraron los oleoductos de la Huasteca Petroleum Co. días antes de la supuesta fecha de la huelga. ${ }^{87}$ Uno puede preguntarse qué mayor agitación laboral podría haber ocurrido si Cárdenas no hubiera nacionalizado la industria petrolera el 18 de marzo, horas antes del plazo final para declarar la huelga. Los trabajadores ya habían tomado las instalaciones petroleras de todo el país: gasolineras, depósitos de distribución, remolcadores, barcazas, camiones, refinerías, pozos, oleoductos, oficinas de las compañías y nóminas de pago. Los extranjeros y mexicanos que habían desempeñado puestos de confianza, fueron expulsados, y los funcionarios sindicales locales nombraron sus propios funcionarios para cubrir puestos de supervisión. La transición fue particularmente vindicativa en las instalaciones de la Huasteca Petroleum Co. Los administradores, amenazados de muerte, huyeron de los campos petroleros. Durante varios días, los dirigentes de la Sección 2

${ }^{87}$ Excélsior, 18 marzo 1938; El Universal, 19 marzo 1938; Daniels a Sec. of State, 17 y 18 marzo 1938, RG 59, 812.5045/697, /726. 
detuvieron a Borrego y Noyola, Ios funcionarios mexicanos de la compañía, hasta que los dirigentes laborales nacionales llegaron para negociar su liberación. ${ }^{88}$ Mientras, la CTM transformó la protesta del 23 de marzo en una celebración del trabajo organizado.

El entusiasmo con que la mayoría de los trabajadores petroleros recibió la expropiación no la puede menguar el hecho de que nunca obtuvieran sus aumentos salariales. Las actividades de los trabajadores de las refinerías y campos petroleros, después de la Depresión đe 1930, muestran que el nivel de salarios, si bien era importante, es posible que haya pasado a segundo plano para la mayoria. Ante todo, el individuo que prestaba sus servicios en la industria petrolera deseaba obtener un puesto de trabajo seguro, y poder abandonarlo a voluntad.

Varias condiciones determinantes del empleo industrial amenazaban a la seguridad laboral. En primer lugar, los jefes de personal decidían a quién contratar, a quién despedir y a quién promocionar, basándose en la capacidad y tal vez también en la docilidad. Al reservar los más altos puestos de la administración para los extranjeros, se establecía un tope al ascenso de los mexicanos más capaces y más trabajadores. Además, los patronos basaban sus decisiones en cuanto a personal, en las condiciones abstractas del mercado. Cuando los precios del petróleo descendían debido a una baja en la de-

88 Mazatán Rodríguez al jefe, 21 y 22 marzo 1938, DAT, caja 180, E1; Daniels a Sec. of State, 24 marzo 1938, RG 59, 812.6363/3120. manda o a un alza en la oferta a escala mundial, las compañías trataban de seguir siendo competitivas recortando los gastos laborales. Así consolidaron y clausuraron instalaciones, $y$ añadieron tecnologías de ahorro de trabajo despidiendo a cientos de obreros. Por último, la competencia por el empleo en los años treinta era muy fuerte $y$ trabajar en la industria del petróleo confería prestigio y prestaciones materiales superiores. El trabajador petrolero, un aristócrata laboral, quería controlar la competencia para mantener su envidiada posición. La Depresión puso en evidencia que muchos campesinos recién salidos del ejido, aspirarían a ingresar en esa industria. Mientras las compañías controlaran el acceso a nuevos puestos, el petrolero mexicano nunca podría tener la seguridad de que su calificación y su experiencia le garantizaran el suyo. Esta fue la razón de que algunos de los obreros más privilegiados de México se convirtieran, en los años treinta, en organizadores sindicales militantes. El deterioro de la industria petrolera mexicana, de propiedad extranjera, había producido la antítesis misma de la seguridad para los proletarios: casi 35000 puestos de trabajo se perdieron entre 1921 y 1935.

Sin embargo, la lucha laboral opuso, con mucha frecuencia, a los mismos miembros de la clase trabajadora. ¿Por qué? Los trabajadores querían controlar al máximo el competitivo mercado de trabajo, y luchaban para evitar los desastrosos despidos masivos. Para lograr estos objetivos, reconstruyeron sus sindicatos fortaleciéndolos y ha. ciéndolos más capaces de enfrentar a 
las compañias. Estas luchas, aunque destructivas, equivalieron a un proceso de selección natural. Los sindicatos surgidos de la lucha de 1934 y 1935 demostraron ser excepcionalmente combativos. Sus dirigentes eran realistas y atrevidos. La lucha ante el taller cerrado satisfizo parte del programa de los trabajadores de base, pero no todos los criterios obreros de seguridad. Mientras las compañias retuvieran el control de personal, los trabajadores no podían tener la seguridad de que sus conquistas no se revirtieran. La misma incertidumbre se aplicaba en el caso de que unos cuantos grupos de patronos privilegiados operaran como compañias sin trabajadores sindicalizados, y de algunos sindicatos sin obtener la claúsula de exclusión. El remedio era obtener un contrato colectivo que limitara severamente las prerrogativas de los patronos. Por lo tanto, en cuanto a seguridad, el trabajador contaba con la protección de su sindicato. Éste le era sin duda más cercano y familiar que la distante e impredecible economía mundial. El Estado tampoco podía proporcionarle -ni la Constitución de 1917, ni la ley laboral de 1931, ni el propio Cárdenas- la seguridad que sí le proporcionaba un sindicato petrolero nacional. Por lo tanto, los trabajadores formaron el STPRM, de abajo hacia arriba por así decirlo.

Pero en el'ínterin, la lucha engendró dos consecuencias inevitables y conocidas: poderosos caciques sindicales de nivel medio y un movimiento laboral politizado. ¿Cómo se pueden explicar estos fenómenos, que, desde entonces, han hecho susceptible al trabajador individual de abuso y manipulación? El trabajador necesitaba un dirigente poderoso e intrépido que pudiera administrar la intensa competencia por los puestos de trabajo. También debía ser capaz de negociar el apoyo de políticos, los mejores, para enfrentar a patrones recalcitrantes. Si el cacique sindical metía la mano en los fondos sindicales, el lío era el mismo de siempre. El trabajador estaba sustituyendo por la tiranía familiar, optimistamente benigna, de un cacique mexicano, la tiranía impersonal de un mercado capitalista internacional que había demostrado ser -en lo que al trabajador se refería- notable. mente desconfiable.

El trabajador también buscó la asistencia del gobierno y de los que competían por el poder para controlar el Estado. Los mexicanos tenían una fuerte tradición en cuanto a buscar remedio a sus quejas: acudir al jefe del pueblo, al jefe político, al gobernador del estado y al propio presidente del país. La imagen de los poderosos patrones extranjeros podría haber reforzado este imperativo político en el México moderno. Había pocas alternativas a la de una fuerte alianza trabajo-Estado si los trabajadores querían oponerse con garantías al dominio de un abominado patrón extranjero. El abuso de los caciques sindicales y la manipulación de los políticos no eran nada nuevo para el trabajador, pero, por lo menos, éstos eran elementos mexicanos. Además los trabajadores ya habían contri. buido antes a deshacerse de malos dirigentes laborales y políticos.

Por su parte, el Estado promovió con Cárdenas la unidad obrera, algo con- 
gruente con su política de equilibrar los "intereses antagónicos" del capital y el trabajo. El Estado cardenista concibió a todos los obreros organizados en grandes sindicatos industriales, como un medio de proporcionar en parte, paz social al mundo industrial. El propio Cárdenas toleraba las huelgas cuando Ios trabajadores estaban organizando los sindicatos. Pero una vez formados, Cárdenas esperaba también que la lucha laboral finalizara, como lo puso de manifiesto en su condena de las huelgas ilegales petroleras. Obviamente el Estado consideraba al sindicato laboral como una forma de disciplina social, mientras que, para el trabajador, era una forma de seguridad social.

Desde estas perspectivas, eera inevitable la expropiación mexicana del petróleo? Tal vez lo fuera a largo plazo, pero el Estado no necesitaba, imperativamente, crear una compañía nacional petrolera en 1938 para lograr la disciplina social. Por su parte, los obreros no la pedían. Ambas partes parecían actuar con el convencimiento de que la propuesta de contrato colectivo de 1936 bastaba para proporcionar seguridad y disciplina. Aparte de lo que los analistas han dicho sobre la soberanía y la emancipación económica, la expropiación petrolera mexicana fue como una argucia histórica. Los intereses petroleros internacionales ya habían empezado a explotar Venezuela y Oriente Medio. En esas circunstancias, las compañías petroleras no pensaban que la industria mexicana del petróleo valiera la pena para ceder en sus prerrogativas tradicionales empresariales. Los mexicanos pen- saban de otro modo y el resto, como ellos dicen, es historia.

\section{Archivos}

-Archivos Nacionales, Washington. D.C.

-Archivo General de la Nación, México.

-Archivo Histórico de Hacienda, México.

\section{BiBLIOGRAFÍA}

-Adelson G., Leif, "Historia social de los obreros industriales de Tampico, 1906. 1919", tesis doctoral, El Colegio de México, México, 1982.

"Coyuntura y conciencia: factores convergentes en la fundación de los sindicatos petroleros de Tampico durante la década de 1920", en Elsa Cecilia Frost et al., El trabajo y los trabajadores en la historia de México, México-Tucson, 1979.

-Brown, Jonathan C., Oil and revolution in Mexico, Berkeley, 1993. "Foreign oil companies, oil workers, and the mexican revolutionary State in the 1920's" en Alice Teichova, et al., Multinational enterprise in historical perspective, Cambridge, 1986.

-Cárdenas, Lázaro, Obras, s/e, México, 1972,3 vols.

-Carr, Barry, El movimiento obrero $y$ la política en México, 1910-1929, Ediciones Era, México, 1976.

-Clark, Marjorie R., Organized labor in Mexico, Chapel Hill, 1934.

-Knight, Alan, "Mexico, c. 1930-1946", The Cambridge History of Latin America, 9 vols., Cambridge, 1982-1989. 
, "The politics of the expropiation" en Jonathan C. Brown y Alan Knight (comps.), The mexican petroleum industry in the twentieth century, Austin, 1992.

-Meyer, Lorenzo, Mexico and the United States in the oil controversy, 1917-1942, Austin, 1977.

-Olvera, AlbertoJ., "Working class culture, Union organization, and petroleum nationalization in Poza Rica, 1932-1940", tesis de maestría, Universidad de Texas, 1988.
-Phillip, George, Oil and politics in Latin America: nationalist movements and state oil companies, Cambridge, 1982.

-Shell International Oil Company, Londres, Group History, México.

-Universidad Obrera de México, El conflicto petrolero en México 1937-1938, México, 1938, 2 vols.

HEMEROGRAFÍA

-El Universal.

-Excélsior. 